\title{
ESTRATÉGIAS PARA A SÍNTESE DE DESOXINUCLEOSÍDEOS
}

Marcos C. Soares, Maria Cecília B. V. de Souza, Vítor F. Ferreira*

Departamento de Química Orgânica, Instituto de Química, Universidade Federal Fluminense, Campus do Valonguinho, Outeiro de S. João Batista s/n, 24020-150 Niterói - RJ

Recebido em 18/2/00; aceito em 16/8/00

STRATEGIES FOR THE SYNTHESES OF DEOXINUCLEOSIDES. The number of agents available for the treatment of viral infections has increased dramatically during the past decade most of them belonging to the nucleoside class. The accomplishment of many syntheses for these nucleosides in recent years offers evidence that the field is very important for the organic synthesis. The discussion of several approaches for preparing deoxy and dehydronucleosides is reviewed in a simplified way.

Keywords: nuclesoside; deoxynucleoside; dehydronucleoside; antiviral.

\section{INTRODUÇÃO}

O termo nucleosídeo foi criado e introduzido no vocabulário científico por Levene e Jacobs em 1909 e, estava originalmente associado aos ácidos nucléicos, dos quais os nucleosídeos foram obtidos pela primeira vez por hidrólise ${ }^{1 \mathrm{a}-\mathrm{c}}$. Os N-nucleosídeos naturais que constituem os ácidos nucléicos compõem-se de um carboidrato - D-ribose ou 2-desoxi-D-ribose - ligado a bases purínicas (N-9) ou pirimidínicas $(\mathrm{N}-3)^{1 \mathrm{a}-\mathrm{c}, 2}$. A hidrólise seletiva, química ou enzimática, de ácidos ribonucléicos (RNA) produz adenosina (1), guanosina (2), citidina (3) e uridina (4).

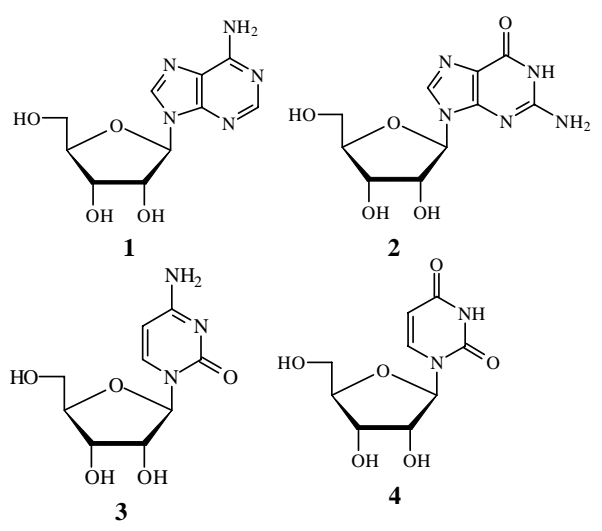

Figura 1. Ribonucleosídeos componentes do RNA.

No caso de hidrólise de ácidos desoxirribonucléicos (DNA), desoxiadenosina (5), desoxiguanosina (6), desoxicitidina (7) e timidina (8) são os nucleosídeos resultantes ${ }^{2 \mathrm{a}}$.

Além dos nucleosídeos mencionados anteriormente, vários outros minoritários podem ser encontrados no DNA e no RNA, como por exemplo, 5-metil-2'-desoxicitidina (9). Destes o mais abundante e também o primeiro $C$-nucleosídeo natural a ser descoberto foi a pseudouridina $(\mathbf{1 0})^{2 a}$. Muitos destes nucleosídeos são metabólitos microbianos, alguns com ação antibiótica ou outras atividades biológicas. Alguns exemplos com propriedades biológicas valiosas são oxetanocina (11, antiHIV), showdomicina (12, antitumoral e antibacteriano), formicina $\left(\mathbf{1 3}\right.$, antitumoral) e pirazomicina $(\mathbf{1 4} \text {, antiviral })^{2 \mathrm{~b}, \mathrm{c}}$.

*e-mail: cegvito@vm.uff.br
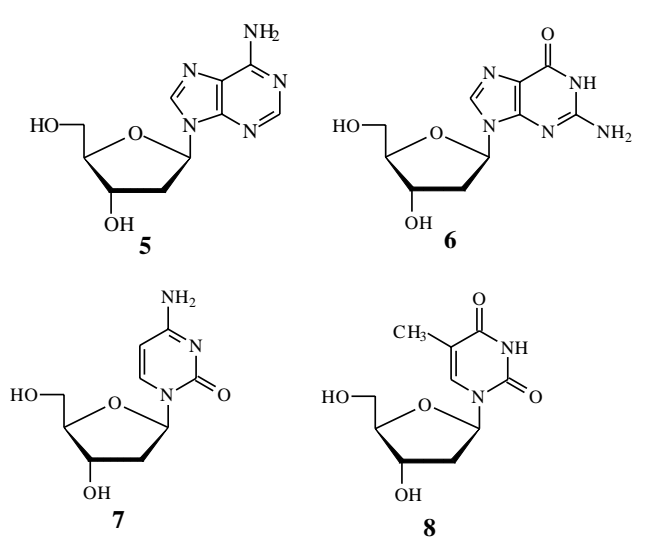

Figura 2. Desoxinucleosídeos componentes do DNA.
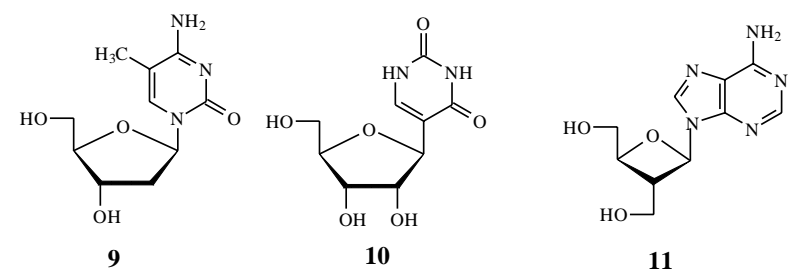<smiles>O=C1C=C(C2OC(CO)C(O)C(O)C2O)C(=O)N1</smiles>

12

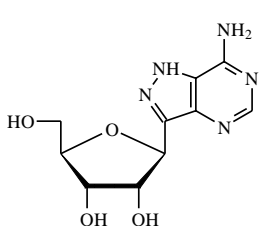

13

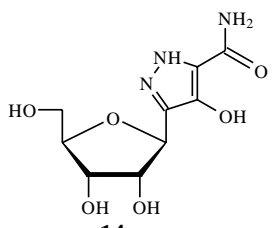

14
Figura 3. Exemplos de nucleosídeos minoritários naturais.

Uma vez que nucleosídeos estão envolvidos nos processos biológicos básicos, alguns análogos sintéticos de nucleosídeos naturais frequientemente exibem atividades biológicas de grande valor farmacêutico. Normalmente, os nucleosídeos que apresentam maior atividade biológica têm o carbono anomérico (C-1') com configuração $\beta$. Alguns exemplos de $\beta$-nucleosídeos utilizados clinicamente são (Figura 4): D-arabinofuranosilcitidina (Ara-C, 15), efetivo contra leucemia mielocítica; aciclovir (16), potente agente anti-herpético, e 3'-azido-3'-desoxitimidina, AZT (17), o composto anti-HIV mais efetivo até hoje ${ }^{2}$. 


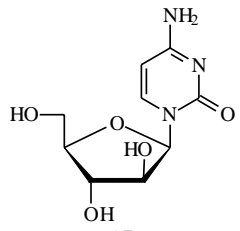

15

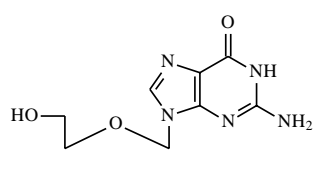

16

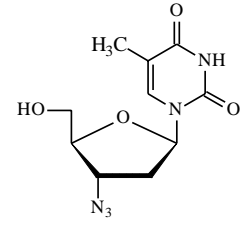

17
Figura 4. Exemplos de análogos de nucleosídeos terapeuticamente úteis.

A química de nucleosídeos, visando principalmente o desenvolvimento de novas substâncias de aplicação terapêutica, tem experimentado grande avanço recentemente. Este progresso está alavancado e orientado pela busca por novos agentes anti-HIV ${ }^{3}$. Neste sentido, como os grupos hidroxilas das posições 3' e 5' dos ribonucleosídeos são indispensáveis para o crescimento da cadeia de DNA, pois atuam como ponto de ligação para a formação da ligação química entre os nucleosídeos, modificações nestes grupos têm sido os alvos mais freqüentes na busca de novos nucleosídeos.

O AZT (17) é um nucleosídeo sintético que não possui a hidroxila da posição 3', sendo assim capaz de interromper a elongação da cadeia do $\mathrm{DNA}^{5}$. Posteriormente à descoberta da ação anti-HIV do AZT, outros análogos nucleosídicos terapeuticamente úteis no tratamento da AIDS foram desenvolvidos. Como exemplos podem ser citadas (Figura 5): 2',3'-didesoxiinosina (ddI, 18); 2',3'-didesoxicitidina (ddC, 19) e a $2^{\prime}, 3^{\prime}$ didesidro-2',3'-didesoxitimidina $(\mathrm{d} 4 \mathrm{~T}, \mathbf{2 0})^{2 \mathrm{a}}$.<smiles>Oc1ncnc2c1ncn2C1CC[C@@H](O)O1</smiles>

18

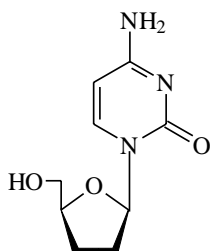

19

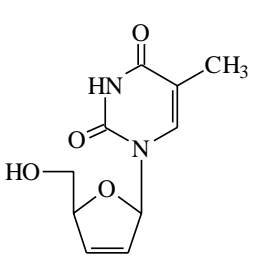

20
Figura 5. Alguns análogos didesoxinucleosídicos com uso terapêutico no tratamento da AIDS.

A atividade anti-HIV destes análogos vem estimulando a pesquisa para o desenvolvimento de métodos para a síntese de 2',3'-didesoxi e 2',3'-didesidro-2',3'-didesoxinucleosídeos bem como para o aprimoramento das rotas sintéticas já existentes para sua obtenção, visando torná-las mais atraentes do ponto de vista econômico-industrial ${ }^{6 a, b}$.

Esta revisão pretende mostrar de forma didática e abrangente as abordagens sintéticas que foram exploradas para a preparação de importantes desoxinucleosídeos por métodos de remoção das hidroxilas das posições C-2'- C-3' dos respectivos ribonucleosídeos. A importância destes desoxinucleosídeos, tanto do ponto de vista acadêmico quanto do industrial, pode ser medida pelo grande número de trabalhos que foram publicados nos últimos anos nesta área. Na maioria destes, as reações de desoxigenação foram realizadas a partir dos ribonucleosídeos previamente preparados por N-glicosilação de bases nitrogenadas. Assim, esta revisão será iniciada com um breve discussão de alguns pontos relacionados à síntese de nucleosídeos.

\section{MÉTODOS DE $N$-GLICOSILAÇÃO}

A metodologia mais utilizada na atualidade para a obtenção de nucleosídeos via reação de acomplamento entre um base nitrogenada $^{7 \mathrm{a}}$ e um carboidrato foi desenvolvida por Vorbrüggen ${ }^{7 \mathrm{~b}-\mathrm{g}}$ e colaboradores na década de 70. Esta se constitui na prévia sililação das bases nitrogenadas, para conferir maior nucleofilicidade ao nitrogênio, seguida de reação com um carboidrato peracilado, sob catálise de um ácido de Lewis (Esquema 1).

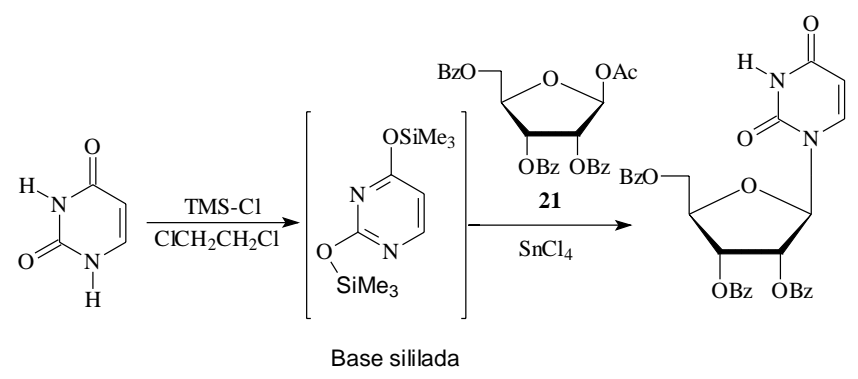

Esquema 1. Exemplo de reação de $\mathrm{N}$-glicosilação pelo método de Vorbrüggen.

Os agentes mais utilizados para a sililação são clorotrimetilsilano (TMS-Cl), hexametildisilazano (HMDS) e $N, O$ bis(trimetilsilil)acetamida (BSA) ${ }^{8}$, sendo que a escolha depende de cada caso em particular. Na etapa de acoplamento, a introdução do uso de carboidratos peracilados em substituição aos halogenados, na presença de ácidos de Lewis como catalisadores, representou um grande avanço na síntese de nucleosídeos. Os C-1-aciloxi-açúcares são mais estáveis do que os C-1-halogenados, em termos de isomerizações, garantindo assim uma maior estereosseletividade na formação da ligação glicosídica ${ }^{8}$. Exemplificando, usando-se 1-O-acetil-2,3,5-tri- $O$ benzoil- $\beta$-D-ribofuranose (21) (Esquema 2), a estereosseletividade pode ser explicada pela formação do intermediário eletrofílico (22), pela ação do ácido de Lewis, o triflato de trimetilsilila. Uma vez formado $\mathbf{2 2}$, o ataque nucleofílico pela base nitrogenada sililada ocorre pela face- $\beta$, não impedida estericamente, levando ao $N$ - $\beta$-nucleosídeo.

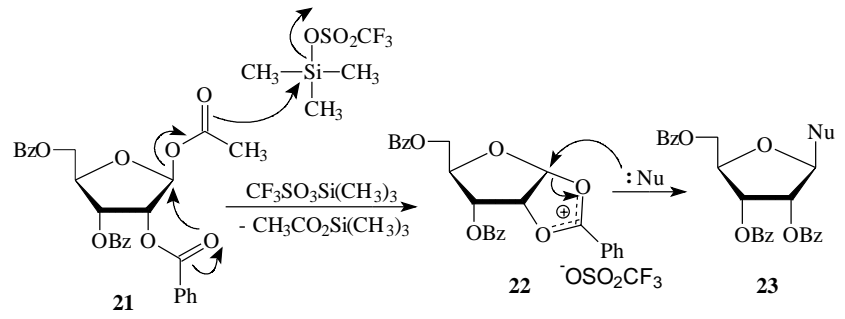

Esquema 2. Formação do intermediário 22 sua seletividade pela face $b^{8}$.

Mais recentemente, Vorbrüggen, com o objetivo de evitar o uso do derivado 21, apesar desta ser uma substância comercialmente disponível, relatou a utilização da D-ribose livre na reação de $\mathrm{N}$-glicosilação ${ }^{9}$. Contudo, os rendimentos foram inferiores aos obtidos pelo método original ${ }^{10}$.

Os ácidos de Lewis mais empregados nas reações de acoplamento são $\mathrm{SnCl}_{4}, \mathrm{AlCl}_{3}, \mathrm{BF}_{3} . \mathrm{Et}_{2} \mathrm{O}, \mathrm{TiCl}_{4}, \mathrm{Me}_{3} \mathrm{SiOSO}_{2} \mathrm{CF}_{3}$ (TMSO-Tf). Publicações mais recentes têm apresentado o uso de outros ácidos de Lewis como catalisadores efetivos em reações de $\mathrm{N}$-glicosilação, dentre estes iodetos metálicos como $\mathrm{SnI}_{2}, \mathrm{SbI}_{2}$ e $\mathrm{TeI}_{2}{ }^{11}$.

Em trabalhos realizados pelo nosso grupo de pesquisa $^{12,13}$, vários ribonucleosídeos derivados do sistema quinolônico foram sintetizados utilizando-se o método de Vorbrüggen modificado. As bases nitrogenadas correspondentes 24a-f foram adequadamente sililadas por reação com $N, O$-bis(trimetilsilil)trifluoroacetamida (BSTFA), este até então pouco utilizado como agente sililante na síntese de nucleosídeos. Em seguida, sofreram reações de $\mathrm{N}$-glicosilação com o derivado da ribose 21, em presença de $\mathrm{SnCl}_{4}$ ou TMSO-Tf como ácidos de Lewis, 
gerando os respectivos nucleosídeos protegidos 25a-f (Esquema 3). Os ribonucleosídeos livres 26a-f foram obtidos por tratamento dos ribonucleosídeos benzoilados 25a-f com solução metanólica de hidróxido de sódio.

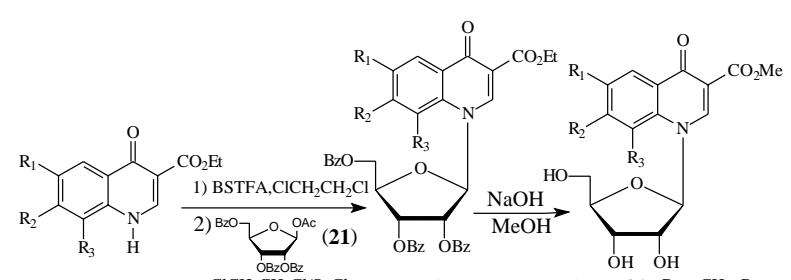

24a, $\mathrm{R}_{1}=\mathrm{CH}_{3} ; \mathrm{R}_{2}=\mathrm{R}_{3}=\mathrm{H}_{\mathrm{ClCH}} \mathrm{CH}_{2} \mathrm{Cl} / \mathrm{SnCl}_{4}$ 25a, $\mathrm{R}_{1}=\mathrm{CH}_{3} ; \mathrm{R}_{2}=\mathrm{R}_{3}=\mathrm{H}(80 \%) \quad$ 26a, $\mathrm{R}_{1}=\mathrm{CH}_{3} ; \mathrm{R}_{2}=$ $\begin{array}{lll}\text { 24b, } \mathrm{R}_{1}=\mathrm{R}_{2}=\mathrm{H}, \mathrm{R}_{3}=\mathrm{CH}_{3} & \text { 25b, } \mathrm{R}_{1}=\mathrm{R}_{2}=\mathrm{H} ; \mathrm{R}_{3}=\mathrm{CH}_{3}(5 \%) & \mathrm{R}_{3}=\mathrm{H}(40 \%)\end{array}$

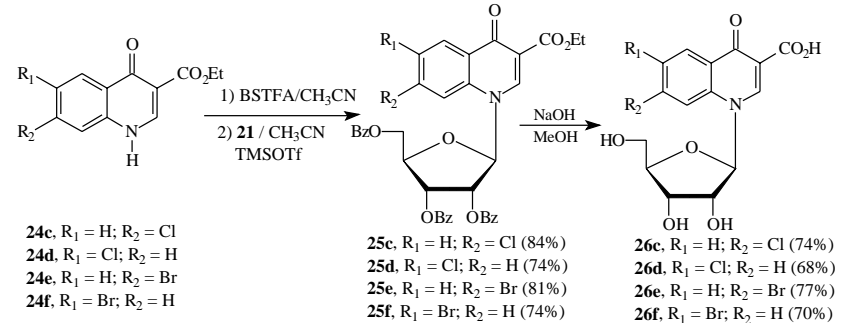

Esquema 3. Síntese de ribonucleosídeos quinolônicos por acoplamento.

\section{ESTRATÉgIAS PARA AS SÍNTESES DE 2',3'-DESOXINUCLEOSÍDEOS E ANÁLOGOS}

Os ribonucleosídeos são dióis cis e vicinais cuja conversão em olefinas pode ser realizada por diversos métodos ${ }^{14}$. Basicamente, esta transformação é viável através de duas metodologias diferentes: conversão direta e conversão a derivados que possam ser mais facilmente desoxigenados.

A conversão direta de dióis vicinais a alcenos pode ser efetuada, por exemplo, com organometálicos derivados do tungstênio $^{14,15}$, titânio ${ }^{16,17}$ ou com oxocomplexos de rênio ${ }^{21}$. Outros métodos utilizam reagentes que realizam derivatização in situ, como por exemplo, cloreto de trimetilsilila/iodeto de sódio $^{18}$, trifenilfosfina/imidazol/iodo ${ }^{19}$ e tribrometo de fósforo/ brometo cuproso/éter, seguida por reação com zinco em pó. ${ }^{20}$ A desoxigenação indireta de dióis vicinais pode ser obtida através de uma conversão prévia em derivados de ésteres sulfonatos $^{22}$, bisditiocarbonatos ${ }^{23}$, tiocarbonatos cíclicos ${ }^{24-27}$, oxiranos $^{28}$, epissulfetos (tiiranos) ${ }^{29-34}$, ortoformiatos cíclicos ${ }^{35}$, fosfatos e fosforamidatos ${ }^{36}$ e sulfatos ${ }^{37-41}$.

\section{MÉTODOS DE CONVERSÃO DIRETA DE DIÓIS VICINAIS A ALCENOS}

Para a conversão direta, o método de Garegg-Samuelsson ${ }^{19}$, iodo-trifenilfosfina-imidazol, é um dos mais suaves e tem sido aplicado com sucesso a ribonucleosídeos. O Esquema $4^{42}$ exemplifica a sua utilização na desoxigenação da dibenziluridina (27). Bons resultados também foram obtidos com os derivados da citosina e timina. Uma variação deste método é o uso de clorodifenilfosfina-iodo-imidazol $^{4 \hat{3}, 44}$. A fácil remoção dos subprodutos, diferentemente do método original de GareggSamuelsson ${ }^{19}$, torna este procedimento mais adequado para preparações em larga escala. A desoxigenação de dióis vicinais com cloreto de trimetilsilila e iodeto de sódio ${ }^{18}$, quando aplicada aos ribonucleosídeos não apresentou resultados aceitáveis ${ }^{45}$.

\section{MÉTODOS DE DESOXIGENAÇÃO COM DERIVATIZAÇÃo PRÉVIA}

Em termos de estratégia sintética, a preparação de 2',3'cloroacetatos na unidade glicosídica é extremamente útil para posterior reação de olefinação entre C2'-C3'. Neste sentido,
Moffatt e colaboradores aplicaram a reação de Mattocks ${ }^{46,47}$ aos ribonucleosídeos e obtiveram os derivados 2-clorados $\mathbf{3 0}$ e $\mathbf{3 1}$ (Esquema 5). Nesta reação, dióis vicinais cis reagem com o cloreto de 2-acetoxi-isobutirila (29) para formar rapidamente trans-cloroacetatos através de íons acetoxônios como intermediários, enquanto trans-dióis levam a misturas complexas de produtos predominantemente não clorados. No caso da uridina (4), formou-se principalmente o produto com estereoquímica cis entre os substituintes acetato e cloro, em consequência da assistência anquimérica do grupo carbonila da posição $2^{\prime}$ da uracila.

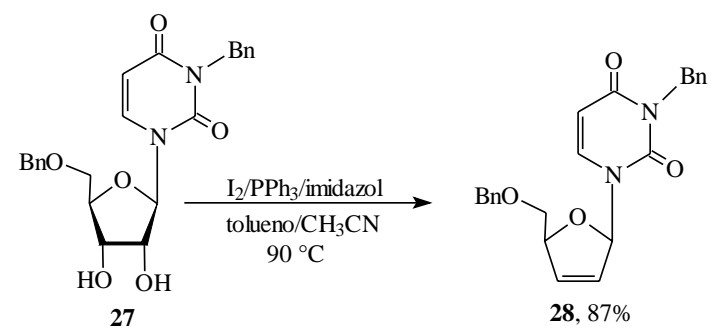

Esquema 4. Aplicação do método de desoxigenação de GareggSamuelsson.

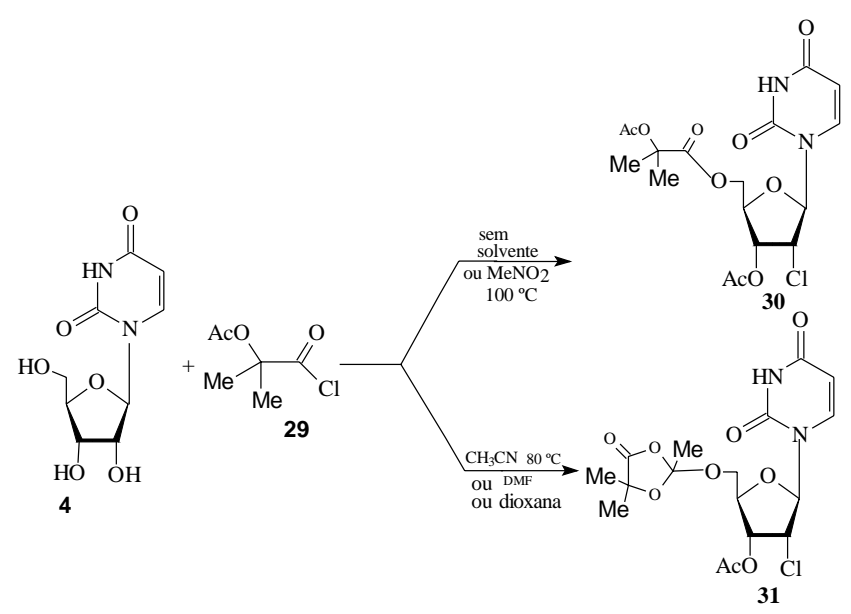

Esquema 5. Reação do cloreto de 2-acetoxi-isobutirila com uridina.

Marumoto e Honjo ${ }^{49 a}$ também sintetizaram o derivado 2'bromo-3',5'-diacetato da uridina (4) utilizando brometo de acetila (32) em acetonitrila (Esquema 6). Resultado semelhante foi obtido por Brokes e colaboradores ${ }^{49 b}$. Chu e Huang ${ }^{50}$ aperfeiçoaram o método através da adição de excesso de brometo de acetila e de ácido bromídrico (30\% v/v) em AcOH, a $55-60{ }^{\circ} \mathrm{C}$. Esta modificação permitiu obter $33 \mathrm{em}$ rendimento superior a $80 \%$.

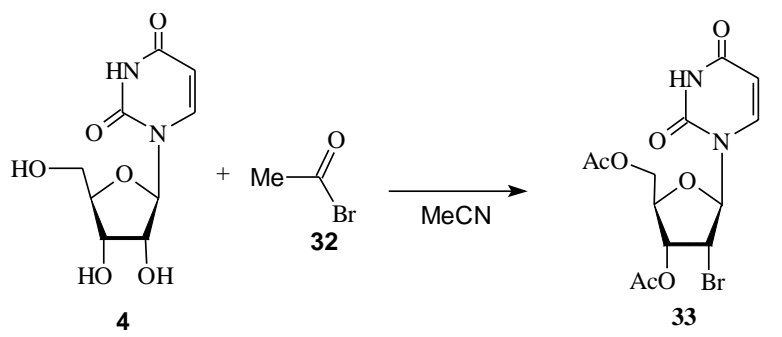

Esquema 6. Reação do brometo de acetila com uridina (4).

Haloésteres também podem ser preparados usando-se tetraacetoxissilano e tribrometo de fósforo nas presenças de eterato de 
trifluoreto de boro $^{51}$ e de brometo de 2-acetoxi-isobutirila para converter adenosina a trans-3'(2')-bromo-2'(3')acetatos ${ }^{52}$. Mansuri e colaboradores ${ }^{53}$ empregaram um método semelhante no qual se utilizava maiores excessos de haleto de acila e aquecimento.

Izawa e colaboradores ${ }^{54}$ desenvolveram um método similar de bromo-acetilação baseado na formação de um orto-éster (34) in situ por reação do ribonucleosídeo com ortoacetato de trimetila (Esquema 7). Esta metodologia previne a formação do subproduto 2',5'-dibromado, observado quando se usa a reação de Mansuri. Na realidade, esta metodologia de metoxietilidenação já havia sido empregada por Robins e colaboradores, sendo pouco explorada pelos autores ${ }^{55-57}$.

Trans-iodoacetatos foram também preparados usando-se uma mistura de cloreto de 2-acetoxi-isobutirila e iodeto de sódio ${ }^{58}$.

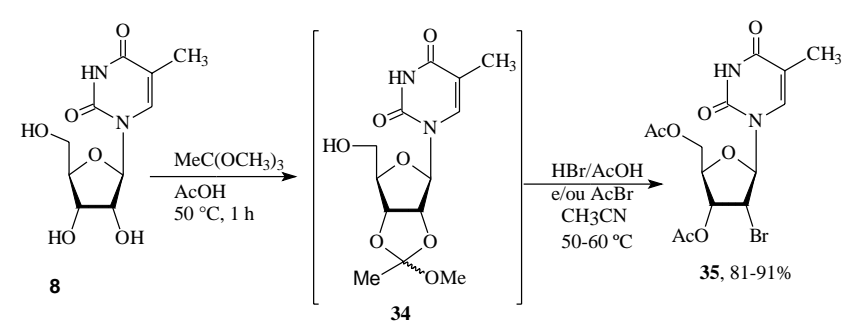

Esquema 7. Método de Izawa para a preparação do bromo-acetato da timidina.

Para a introdução da ligação dupla entre os carbonos C2',C3', a partir de haloésteres, o processo mais comum é a eliminação redutiva. Neste, a clivagem da ligação N-glicosídica é um problema encontrado pois compete com a eliminação 2',3'. Por exemplo, a redução do bromo-acetato da timidina $(\mathbf{3 5})^{53}$ formou o desoxinucleosídeo desejado em $53 \%$ de rendimento. Porém, ocorreu extensiva quebra da ligação $N$ glicosídica, isolando-se ao fim da reação a timina (36) em $40 \%$ de rendimento (Esquema 8).

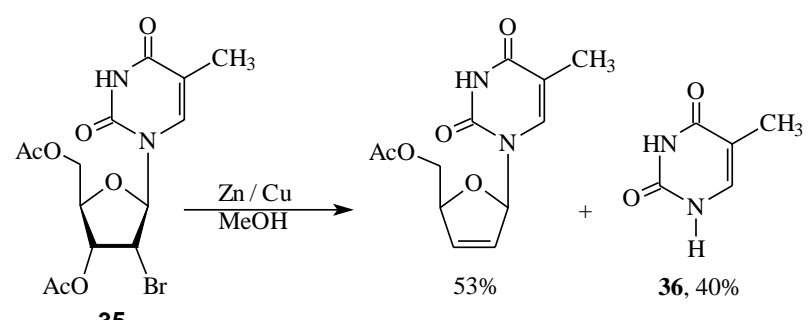

Esquema 8. Eliminação redutiva no haloéster 35 , acompanhada de quebra da ligação glicosídica.

Neste caso, a ruptura da ligação $\mathrm{N}$-glicosídica poderia ser conseqüência da instabilidade do nucleosídeo nas condições reacionais ou o resultado da competição entre a eliminação da base nitrogenada, do tipo trans-b, e a desejada eliminação do tipo cis-b entre as posições C2' e C3'. Para testar esta hipótese, foi desenvolvida uma síntese, via epóxido 37, obtendo-se um trans-bromoacetato $(\mathbf{3 8})^{60}$ (Esquema 9). A reação deste derivado trans (38) se mostrou mais eficiente, indicando que a eliminação trans-b realmente compete com a olefinação entre C2' e C3'.

A escolha do grupo protetor para a hidroxila da posição 5, é fundamental para o sucesso da sequência haloéster $\rightarrow$ olefina $\rightarrow$ nucleosídeo final. No caso apresentado no Esquema 9, a tentativa de hidrólise do mesilato 39 usando-se solução de hidróxido de sódio levou à formação do derivado furânico indesejável (40), possivelmente, segundo os autores ${ }^{60}$, devido ao ataque

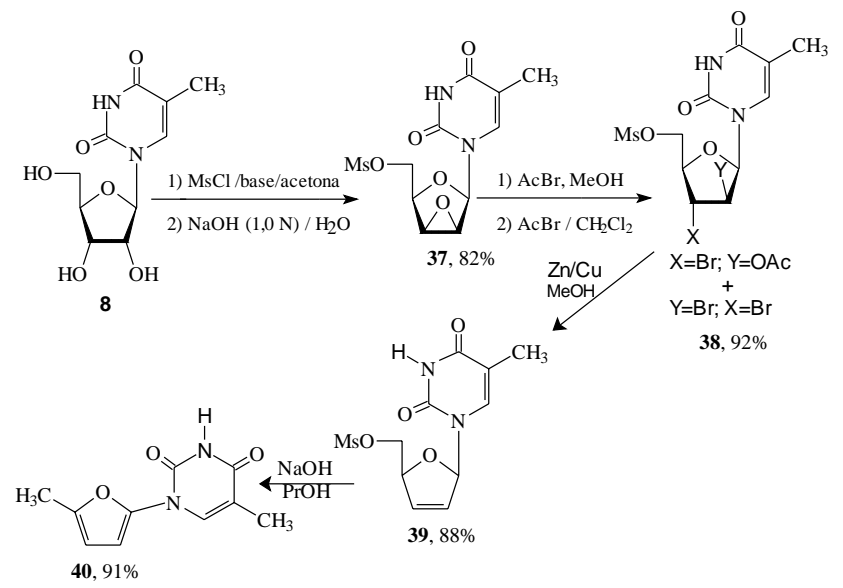

Esquema 9. Utilização do 2',3'-trans-bromoacetato da timidina na eliminação.

do ânion hidróxido ao hidrogênio da posição 4', seguido de aromatização. Esta dificuldade foi contornada utilizando-se uma base mais fraca como o benzoato de sódio.

Como indicado anteriormente, haloésteres de nucleosídeos podem ser intermediários-chaves para a síntese de importantes antivirais. Entretanto, a etapa mais importante é a eliminação redutiva devido à labilidade de toda a estrutura do nucleosídeo. Assim, vários métodos foram desenvolvidos visando melhorar o rendimento desta etapa de eliminação redutiva. Moffatt e colaboradores $^{61}$ empregaram o método de Kochi ${ }^{62}$ para sintetizar 2',3'-didesidro-2',3'-didesoxinucleosídeos, como o d4U (42), a partir do derivado bromoacetato da uridina (41). Este método consiste no tratamento do bromoéster com o complexo de acetato de cromo (II)/etilenodiamina, obtendo-se $\mathbf{4 2} \mathrm{em}$ baixo rendimento (Esquema 10).
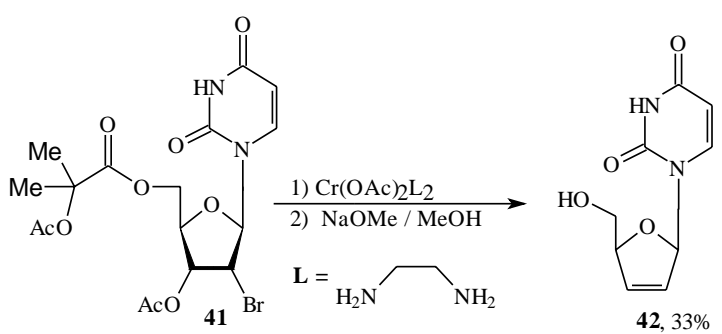

Esquema 10. Eliminação redutiva promovida por complexo de cromo (II).

As eliminações eletroquímica e por transferência de elétrons também foram aplicadas a derivados iodoacetatos da formicina, pivaloil adenosina ${ }^{58}$, bem como ao bromoacetato da adenosina ${ }^{63}(\mathbf{4 3})$ levando aos produtos olefínicos em bons rendimentos (Esquema 11), conforme exemplificado para a síntese do d4A $(\mathbf{4 4})^{58,63}$.

Vários experimentos de eliminações em bromoacetatos, usando-se o zinco em pó em meio de ácido acético e etanol ${ }^{64}$, liga zinco-cobre $(\mathrm{Zn} / \mathrm{Cu})^{52}$ e outras variações experimentais (solventes, ligas metálicas, temperatura, etc.) foram testados. Deste modo, o nucleosídeo 44 foi obtido em $95 \%$ de rendimento (Esquema 11). Esta redução também foi empregada por Mansuri e colaboradores ${ }^{53}$ para as sínteses de d4U (42) e d4A (44) a partir de derivados bromoacetatos contendo diferentes substituintes na posição 5'. Estes mesmos autores mencionam que a reação com $\mathrm{Zn} / \mathrm{Cu}$ pode ser feita em $\mathrm{MeOH}$ ou THF ao invés de DMF. Isto é especialmente útil em preparações em escala maior do que a laboratorial visto que volumes maiores 


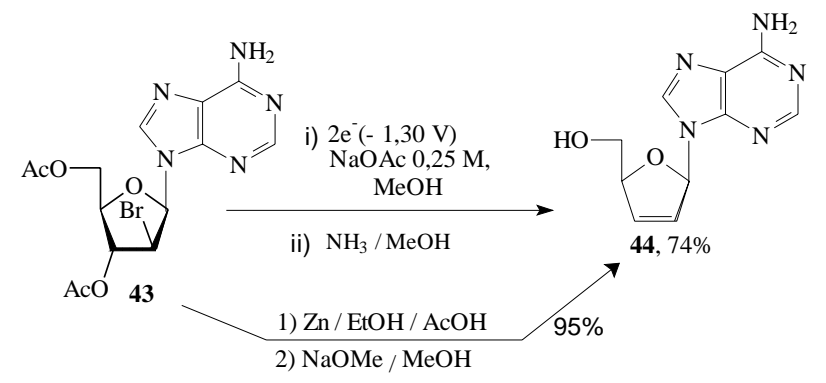

Esquema 11. Eliminações eletroquímica e por transferência de elétrons.

de solventes podem ser removidos a temperaturas mais baixas, evitando-se exposição prolongada a altas temperaturas que pode levar à ruptura da ligação glicosídica ${ }^{65-69}$.

Uma das desvantagens do uso de zinco como redutor é a formação de um gel durante o tratamento com água, tornando a purificação do produto trabalhosa, além de se ter o zinco como contaminante do produto final. Para contornar estas dificuldades foi introduzido o ácido etilenodiaminotetra-acético (EDTA) como extrator do metal residual ${ }^{54}$. A grande dificuldade para o uso da liga $\mathrm{Zn} / \mathrm{Cu}$ previamente preparada ou gerada in situ ${ }^{70}$ é a não reprodutibilidade dos resultados da reação e a formação de vários subprodutos. Dificuldades idênticas foram encontradas em reações deste tipo realizadas por nosso grupo ${ }^{71}$, mesmo com a utilização da liga $\mathrm{Zn}-\mathrm{Cu}$ gerada no meio reacional.

O uso de sistema bifásico mediando reações de transferência de elétrons (oxi-redução) é um interessante método de eliminação redutiva do tipo- $\beta$ em 2',3'-acetoxi-bromonucleosíde$\mathrm{os}^{72}$, fornecendo nucleosídeos 2',3'-insaturados em rendimentos entre $64-83 \%$.

Foi observado que a eliminação redutiva de tosilato de trans-2-bromocicloexila com zinco é mais rápida do que a do acetato $^{73}$ correspondente. Assim, com base nesta observação, foi desenvolvido um método, embora não direto mas com bom rendimento, para a obtenção do d4T (20) passando pelo bromomesilato 45a como intermediário (Esquema 12) ${ }^{74}$.

Derivados halogeno-acetoxi de nucleosídeos podem também ser convertidos diretamente a 2',3'-didesidro-2',3'-didesoxinucleosídeos por hidrogenólise catalítica. Assim, por exemplo, paládio sobre sulfato de bário foi usado como catalisador para a hidrogenólise do bromomesilato da uridina (45b) (Esquema 12) ${ }^{48}$. Nesta hidrogenólise catalítica, um bom grupo abandonador vizinho ao halogênio, como neste caso de 45b, produz o 2'-3'-didesoxinucleosídeo (20) em bom rendimento $^{75}$. Em várias outras sínteses a hidrogenólise de haloésteres ou mono haletos com $\mathrm{Pd} / \mathrm{C}$ foi utilizada como etapa chave na preparação de 2'-3'-didesoxinucleosídeo em bons rendimentos ${ }^{76-81}$.

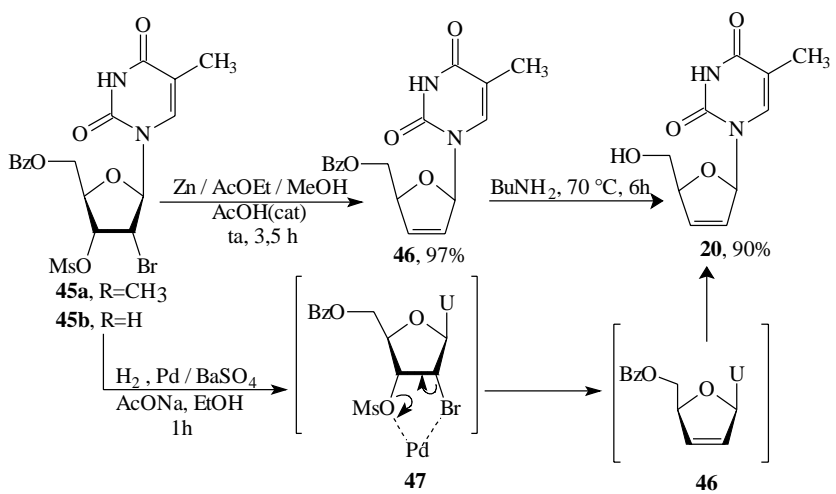

Esquema 12. Eliminação redutiva e hidrogenólise em halo-mesilatos.
No nosso grupo de pesquisa foi explorado o uso da hidrogenação com paládio sobre carbono para efetuar a conversão do derivado bromoacetato 48 , via intermediário 49 gerado in situ, ao didesoxinucleosídeo $\mathbf{5 0}$ (Esquema 13) ${ }^{71}$. Entretanto, com ambas as condições empregadas (a e b) ocorreu clivagem da ligação $\mathrm{N}$-glicosídica com a formação de vários subprodutos.

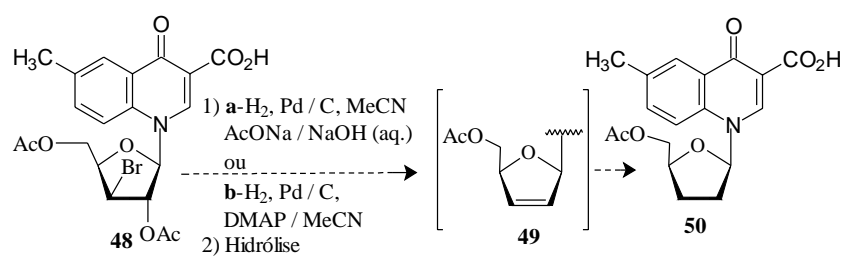

Esquema 13. Hidrogenólise em nucleosídeo quinolônico.

O hidreto de tributilestanho é um reagente muito utilizado em reações de desalogenações seletivas, inclusive quando gerado catalicamente no meio reacional ${ }^{82}$. Este hidreto foi usado por Brokes e seus colaboradores ${ }^{49 b}$ para a síntese da 2'desoxiuridina (53). Uma versão catalítica deste método foi empregada por Chu e Huang ${ }^{50}$, com o mesmo propósito, usando azobisisobutironitrila (AIBN) como iniciador do mecanismo radicalar. $\mathrm{O}$ agente desalogenante, hidreto de tributilestanho, é gerado in situ por reação entre cloreto de tributilestanho e boroidreto de sódio (Esquema 14). Hidreto de tributilestanho também foi empregado para a preparação da 2'desoxiadenosina e 3'-desoxiadenosina a partir das misturas dos respectivos bromoésteres ${ }^{66,69 a, b}$.

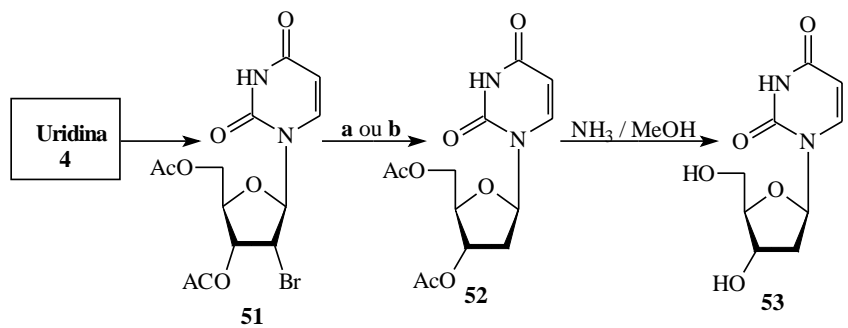

a (ref. 50b): $\mathrm{Bu}_{3} \mathrm{SnH}$, benzeno, refluxo, $\quad$ b (ref.51) : $\mathrm{Bu}_{3} \mathrm{SnCl}_{\mathrm{NaBH}}, \mathrm{EtOH}$, 2,2'-azo-bis(2-metilproprionitrila), $\quad$ (76\% a partir da uridina, 4 ).

( $46 \%$ a partir da uridina, 4$)$.

Esquema 14. Desalogenação de bromoacetatos com $\mathrm{Bu}_{3} \mathrm{SnH}$.

\section{DESOXIGENAÇÕES RADICALARES: O MÉTODO DE BARTON-MCCOMBIE}

Com base no mecanismo de fotoeliminação de $O$-alquiltiobenzoatos, Barton e McCombie desenvolveram um processo voltado para a desoxigenação radicalar de ésteres, normalmente tioésteres, tendo um hidrogênio na posição $\beta$, para formar uma olefina (Esquema 15) ${ }^{83,84}$.

Quando a reação radicalar é iniciada por um radical $\mathbf{M}$. capaz de formar uma ligação estável com o enxofre da tiocarbonila origina-se um radical intermediário que se fragmenta em um radical alquila e um composto carbonílico. A força motriz da reação seria a energia ganha pela transição de uma ligação dupla $\mathrm{C}=\mathrm{S}$ para $\mathrm{C}=\mathrm{O}$. Radicais trialquilestanho, formados a partir dos hidretos de estanho $\left(\mathrm{R}_{3} \mathrm{SnH}\right)$, são particularmente adequados porque a ligação $\mathrm{Sn}-\mathrm{S}$ é muito estável e hidretos de trialquilestanho também são excepcionalmente bons doadores de radical hidrogênio (Esquema 15) ${ }^{84}$.

A natureza do substituinte $\mathbf{X}$ é determinante do caminho a ser seguido pela reação. Radicais $[\mathrm{ROC}(\mathrm{SM}) \mathrm{X}]^{\cdot}$ pouco estáveis $(\mathrm{X}=\mathrm{H}, \mathrm{Me})$ reagem com o hidreto pelo caminho $\mathbf{B}$, gerando o 

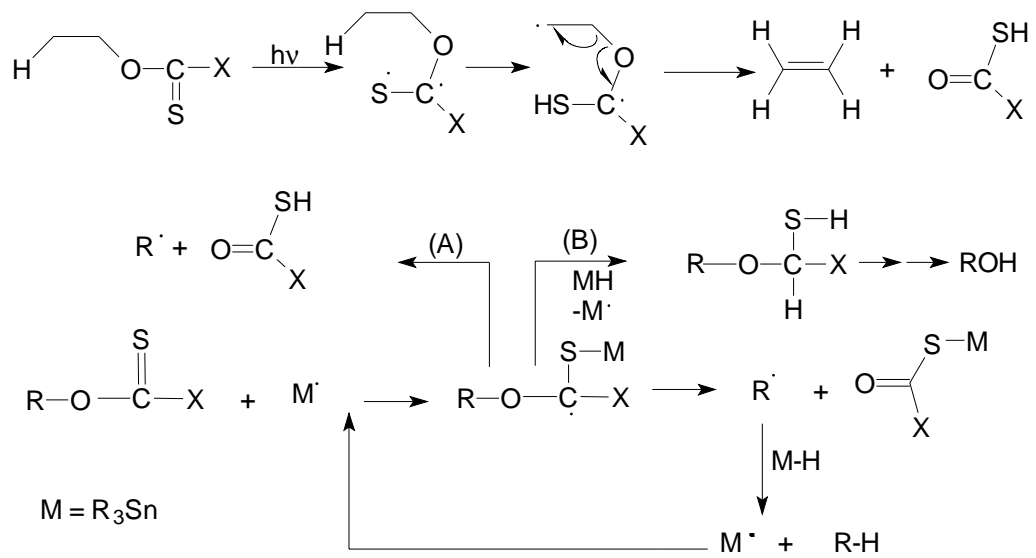

Esquema 15. Mecanismo de eliminação de Barton-McCombie em tioésteres.

álcool. Substituintes que estabilizam radicais $(\mathrm{X}=\mathrm{Ph}, \mathrm{S}-\mathrm{Me})$ estendem o tempo de vida deste intermediário, favorecendo a fragmentação (via $\mathbf{A})^{84}$.

A desoxigenação via um derivado tioformil $(X=H$, figura 6) pode ser realizada quando o grupo de saída radicalar R' é estabilizado por grupos vizinhos como por exemplo, grupos alquila o fazem na desoxigenação de álcoois terciários ${ }^{84,85}$, ou por efeito do oxigênio de uma ligação C-O em posição $\beta^{4,86}$, como ocorre na desoxigenação de carboidratos.

Vários tioésteres 54 (Figura 6) foram utilizados nas reações de desoxigenação como: tioformiato $(\mathbf{a})^{84}$, tioacetato $(\mathbf{b})^{84}$, xantato ou $S$-metilditiocarbonato $(\mathbf{c})^{83}$, feniltionocarbonato (ou tiobenzoato, ou tionobenzoato) (d) ${ }^{83}$, imidazolotionocarbonato (ou melhor,

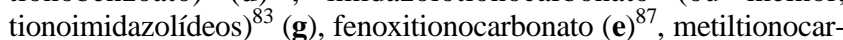
bonato $(\mathbf{f})^{88}, p$-metilfenoxitionocarbonato $(\mathbf{h})^{89}, 2,4,6$-triclorofenoxitionocarbamato $^{90}(\mathbf{j})$, pentafluorofenoxitiocarbonato ${ }^{90}(\mathbf{k}), p$-fluorofenoxitionocarbonato $^{91}(\mathbf{i})$, tionocarbamato ${ }^{92}$ (l). Entre eles, os derivados $S$-metilditiocarbonato (54c), feniltionocarbonato (54d), e $p$-fluorofenoxitionocarbonato (54i) de álcoois são os mais freqüentemente usados devido a sua reatividade e facilidade de preparação ${ }^{94}$. Selenocarbamatos $(\mathbf{5 5})$ também foram utillizados ${ }^{93}$.

Tionocarbamatos $\left(\mathbf{5 4 l}, \mathrm{R}_{1}=\mathrm{H}, \mathrm{R}_{2}=\right.$ morfolino, por exemplo) se mostraram inertes sob condições normais de reação com hidreto de tributilestanho (tolueno, refluxo). ${ }^{84}$ Esta falta de reatividade em reações radicalares é atribuída à baixa radicofilicidade da ligação $\mathrm{C}=\mathrm{S}$, quando ocorre deslocalização do par de elétrons não-compartilhados do nitrogênio sobre a ligação dupla carbono-enxofre. Para tentar contornar esta dificuldade foi proposto o uso dos selenocarbamatos $(\mathbf{5 5})^{93}$. Contudo, o seleno radical intermediário mostrou-se bastante estável de modo que a clivagem homolítica da ligação carbonooxigênio não ocorreu ${ }^{93}$.

O método de Barton-McCombie, quando aplicado a tionocarbonatos cíclicos derivados de dióis vicinais leva a produtos monodesoxigenados ${ }^{23,9}$.

A remoção do grupo $3^{\prime}$-hidroxi de $2^{\prime}$-desoxiribonucleosídeos tem sido efetuada por esta rota de desoxigenação, constituindo-se em um método rápido de preparação dos didesoxinucleosídeos $^{84,96,97}$. O tratamento do tionocarbonato cíclico $\mathbf{5 5}$ com hidreto de tributilestanho leva à formação de uma mistura dos produtos monodesoxigenados 56 e $\mathbf{5 7}$, como mostrado no Esquema 16. A mistura de produtos desta reação é convertida em novos tioésteres e estes são resubmetidos à eliminação redutiva para produzirem o 2',3'-didesoxinucleosídeo.

A desoxigenação de Barton-McCombie pode ser seletiva, conforme mostrado na reação do tionocabonato cíclico do glicofuranosídeo $\mathbf{5 8}$ com hidreto de tributilestanho. Forma-se exclusivamente o produto C-5-desoxi 59. Esta seletividade é atribuída à maior estabilidade do radical secundário $\left(\mathrm{em}^{\mathrm{C}_{5}}\right.$ ) quando comparada a do radical primário $\left(\right.$ em $_{6}$ ) (Esquema 17) ${ }^{84,98,99}$.<smiles>[R]OC(=S)O[13C]([Y4])=S</smiles>

$54 \mathrm{I}=\mathrm{NR}_{1} \mathrm{R}_{2}$

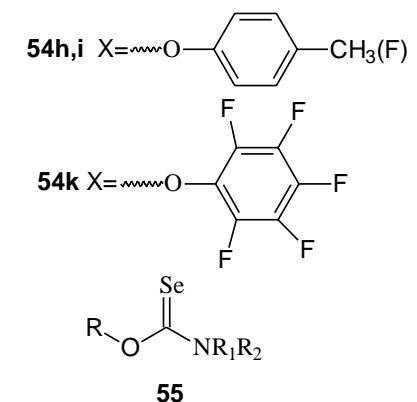

Figura 6. Derivados usados na desoxigenação de Barton-McCombie.

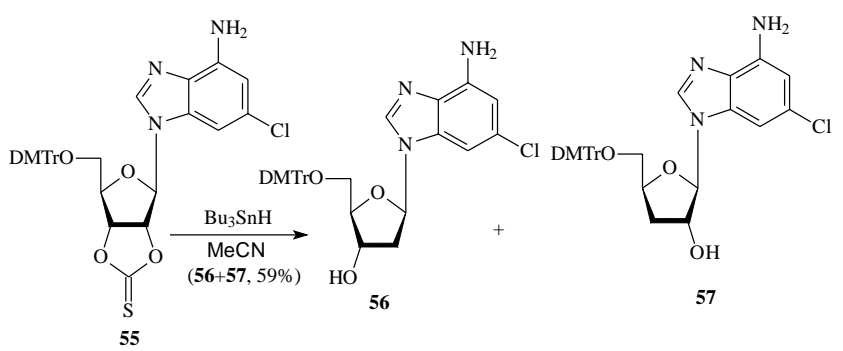

Esquema 16. Desoxigenação de Barton-McCombie em tionocarbonatos cíclicos.

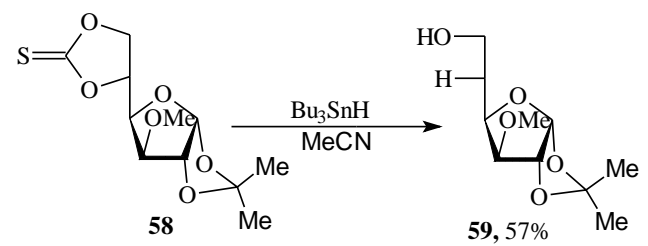

Esquema 17. Desoxigenação seletiva em um tionocarbonato cíclico.

Um segundo método muito versátil envolve o uso de mono ou bisxantato em lugar de tionocarbonatos. $\mathrm{O}$ bisxantato oferece a vantagem de formar diretamente o desoxinucleosídeo 2',3'insaturado, como por exemplo, na transformação de $\mathbf{6 0} \mathrm{em} \mathrm{61}$, em altos rendimentos (Esquema 18) ${ }^{83,84}$. Outras conversões 
similares de 2',3'-dicloronucleosídeos ${ }^{3}$ e $2^{\prime}$-cloro ou 2'(3')bromo-3'(2')-[(fenoxitiocarbonil)oxi]nucleosídeos ${ }^{3,68,100,101}$ assim como aquelas de 2'(3')-desoxi-2'(3')- [(fenoxitiocarbonil) oxi]nucleosídeos ${ }^{101,102}$ foram também reportadas (Esquema 18).

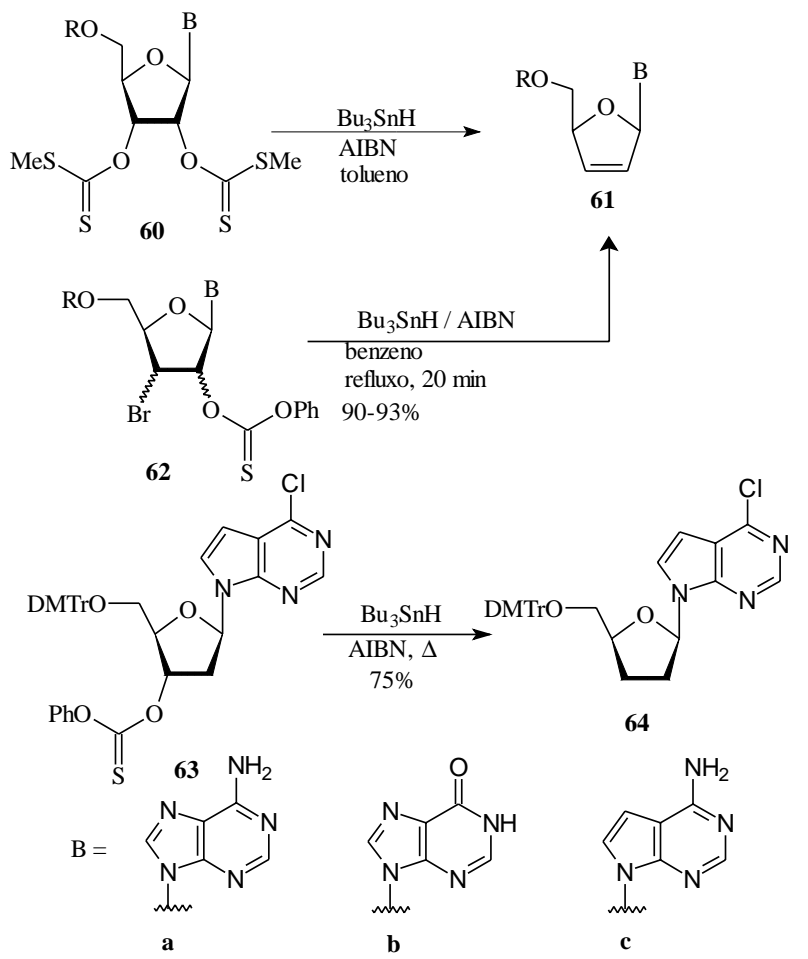

Esquema 18. Reação de desoxigenação radicalar com mono ou bisxantato.

Sekine e Nakanishi ${ }^{103}$ utilizaram o grupo fenoxitionocarbonílico tanto para proteção da posição 5' quanto para ativação da timidina numa reação de redução com hidreto de tributilestanho. Isto foi possível porque usando-se uma quantidade controlada do agente redutor, ocorre a remoção regiosseletiva do grupo em 3' (Esquema 19). Tal comportamento está de acordo com o que se esperaria da maior estabilidade de um radical intermediário secundário, resultante do ataque à posição 3', frente a do radical primário que resultaria se a redução se desse na posição $5^{\prime}$. O hidreto de tributilestanho pode também ser gerado in situ $^{88}$ diminuindo a formação de subprodutos.

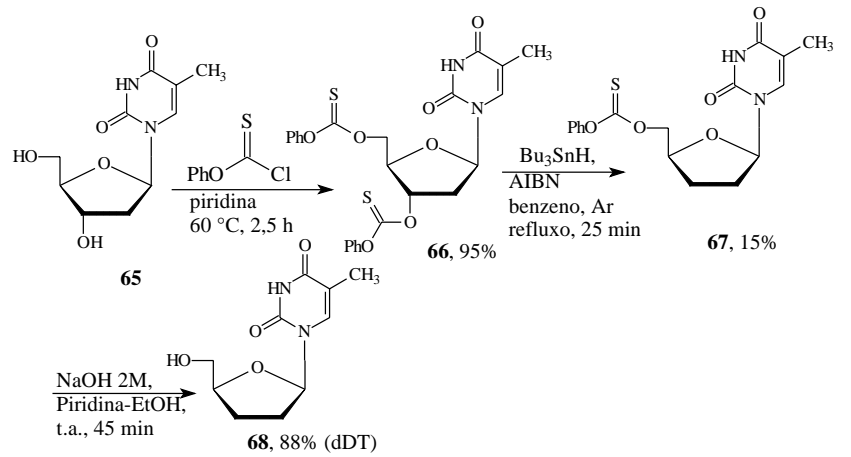

Esquema 19. Síntese do dDT por redução regiosseletiva de um fenoxitionocarbonato.

Embora a desoxigenação de Barton-McCombie seja conveniente e amplamente utilizada, a necessidade de uso de hidreto de tributilestanho é problemática porque resulta em contaminação do produto final com estanho, além de gerar resíduos tóxicos. Etapas adicionais são geralmente necessárias para garantir que o produto esteja livre destes contaminantes tóxicos. Devido a estas dificuldades vários esforços vêm sendo feitos para reduzir o seu uso ${ }^{104}$ ou substituí-lo totalmente ${ }^{91,92,94,105-118}$. Um método que usa quantidades catalíticas de hidreto de tributilestanho foi desenvolvido por Fu e colaboradores. ${ }^{104}$ Neste, o hidreto é empregado como catalisador juntamente com um agente redutor que é usado em quantidade estequiométrica (Esquema 20). A redução de um tionocarbonato (69) pelo hidreto de tributilestanho gera COS, o produto desoxigenado e $\mathrm{Bu}_{3} \mathrm{Sn}(\mathrm{OPh})$. Este último reage então com o redutor estequiométrico $(\mathrm{M}-\mathrm{H})$ para regenerar o catalisador $n-\mathrm{Bu}_{3} \mathrm{SnH}$. Para esta reciclagem do hidreto de tributilestanho foi empregado polimetilidrosiloxano (PMHS).

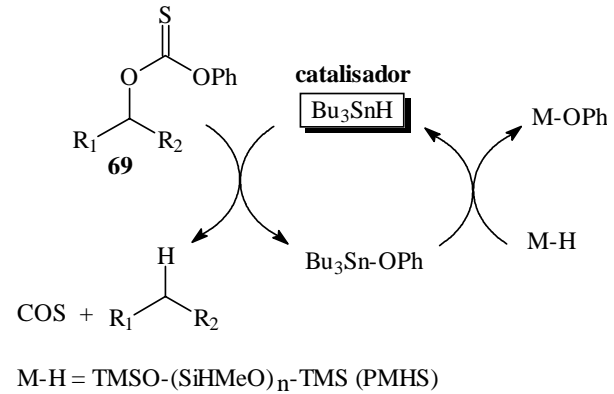

Esquema 20. Reação de Barton-McCombie com reciclagem de Bu $u_{3} \mathrm{SnH}$.

O uso de hidretos de silício em substituição ao hidreto de tributilestanho foi uma possibilidade bastante considerada. Porém, havia dúvidas se a ligação $\mathrm{Si}-\mathrm{H}$ de um silano seria suficientemente fraca para permitir a formação do radical correspondente, necessário à reação em cadeia. ${ }^{105}$ Embora alquilsilanos simples tenham ligação $\mathrm{Si}-\mathrm{H}$ relativamente forte $\left(377 \mathrm{~kJ} \mathrm{~mol}^{-1}\right.$ para o $\left.\mathrm{Et}_{3} \mathrm{SiH}\right)$, estes compostos podem ainda ser usados em reações de desoxigenação radicalares. Assim, Roberts e colaboradores ${ }^{106-108}$ descreveram o emprego de trimetilsilano em tais reações. Em contraste ao $\mathrm{BuSn}_{3} \mathrm{H}$, o trietilsilano é ineficaz para gerar radicais livres sob condições similares, porque o ciclo de propagação da reação em cadeia é lento $\left(\mathrm{R}^{\cdot}+\mathrm{Et}_{3} \mathrm{SiH}\right)$. O problema da propagação da cadeia de radicais livres pelo $\mathrm{Et}_{3} \mathrm{SiH}$ foi resolvido com a utilização de alquiltióis como catalisadores, pois a reação $\mathrm{RS} \cdot+\mathrm{Et}_{3} \mathrm{SiH} \rightarrow \mathrm{RS} \cdot+\mathrm{Et}_{3} \mathrm{SiH}$ é rápida.

Uma outra alternativa para manter esta reação em cadeia é a adição de porções de peróxido de benzoíla à mistura reacional ${ }^{105}$. Este método foi aplicado a derivados de carboidratos, esteróides e nucleosídeos, com rendimentos do produto desoxigenado variando entre $82-100 \%$, conforme mostrado na desoxigenação do bisxantato da adenosina (70, Esquema 21).

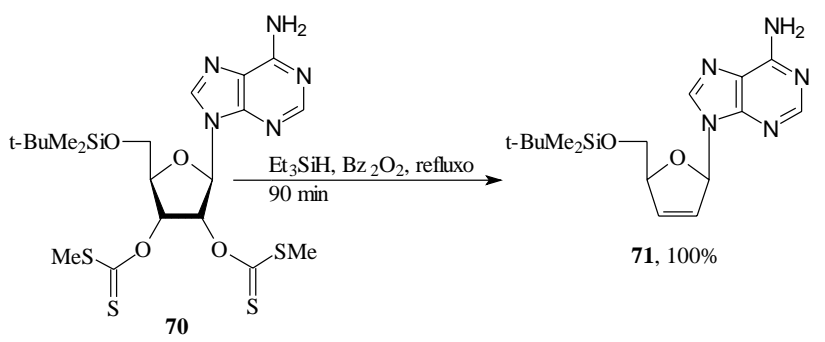

Esquema 21. Desoxigenação de bisxantato com o sistema $\mathrm{Et}_{3} \mathrm{SiH}_{\mathrm{Bz}} \mathrm{O}_{2} \mathrm{O}_{2}$. 
Outro sistema redutor-iniciador como trietilsilano-peróxido de di-tert-butila (DTBP) funciona bem na desoxigenação de tionocarbamatos preparados pela reação entre álcoois e isotiocianatos, ao contrário do que ocorria com o uso hidreto de tributilestanho. Tris(trimetilsilil)silano tem se mostrado um bom substituto para o hidreto de tributilestanho. ${ }^{109}$ Neste composto, a ligação $\mathrm{Si}-\mathrm{H}$ é relativamente mais fraca $\left(331 \mathrm{KJ} \mathrm{mol}^{-1}\right)$ do que, por exemplo, no trietilsilano $\left(377 \mathrm{KJ} \mathrm{mol}^{-1}\right)^{106}$. Fenilsilanos disponíveis comercialmente como fenilsilano ${ }^{110}$, difenilsilano ${ }^{109-112}$ e trifenilsilano ${ }^{113}$ funcionam bem em desoxigenações radicalares, como redutores, e propagadores da reação em cadeia.

A desoxigenação do metilxantato da diacetona glicose (72) foi utilizada como modelo para muitas das reações de desoxigenação radicalares empregando-se silanos. A Tabela 1 permite uma comparação entre os diversos métodos. Nela, pode-se observar que os rendimentos das reduções são bons, demonstrando que os silanos também são excelentes redutores quando comparados a hidretos de triaquilestanho.

Um outro grupo de agentes redutores pesquisados para estas reações de desoxigenação radicalares são compostos que possuem a ligação P-H, principalmente compostos de fósforo (III). Fosfitos de alquila foram usados com sucesso ${ }^{114}$ como redutores em reações de desoxigenação de tionocarbonatos e de xantatos de álcoois primários e secundários. Peróxido de benzoíla foi utilizado como iniciador, o que não é problema em pequena escala mas dificulta o trabalho no caso do uso de quantidades maiores de reagentes ${ }^{114,115}$. Outros compostos de fósforo (III) empregados foram: ácido fosforoso, $\mathrm{H}_{3} \mathrm{PO}_{2}$, e seus sais. Nestas reações podese usar AIBN como iniciador, em lugar do peróxido de benzoíla. Normalmente, as reações são feitas em presença de uma amina terciária, para proteger grupos sensíveis a ácidos que estejam presentes na molécula. Ácido hipofosforoso não é aplicável a substratos sensíveis à umidade devido às dificuldades de completa remoção da água presente no reagente $\mathrm{e}^{115,116}$.

Um diol vicinal, 1,2;5,6-di- $O$-isopropilidenomanitol, foi desoxigenado à olefina correspondente em $78 \%$ de rendimento através do seu respectivo bisxantato, pelo uso de ácido fosforoso/trietilamina. A desoxigenação de álcoois pode também ser realizada com óxido de di-butilfosfina, originando os produtos desejados em altos rendimentos. As vantagens do processo são: a aplicabilidade de vários iniciadores de radicais; o fato de não ser necessário o uso do redutor em excesso e a exclusão completa de umidade ${ }^{94}$.

Outro reagente fosforado capaz de promover desoxigenação em rendimentos razoáveis foi desenvolvido por Jang e colaboradores ${ }^{117}$ que empregaram óxido de difenilfosfina, $\mathrm{Ph}_{2} \mathrm{P}(\mathrm{O}) \mathrm{H}$ (Tabela 2). Complexos de fosfina-boranos $\left(\mathrm{R}_{3} \mathrm{P} \cdot \mathrm{BH}_{3}\right)$, na presença de AIBN como iniciador, foram testados para a desoxigenação

Tabela 1. Redução do metilxantato da diacetona glicose (72) com silanos.

\begin{tabular}{|c|c|c|c|}
\hline REDUTOR (eq.) & CONDIÇÕES & $(\%)$ & REF. \\
\hline $\mathrm{Et}_{3} \mathrm{SiH}(47)^{\mathrm{a}}$ & $\mathrm{Bz}_{2} \mathrm{O}_{2}$ (1 eq.), Ar, $2,5 \mathrm{~h}$ & $96^{\mathrm{b}}$ & 105 \\
\hline $\mathrm{Et}_{3} \mathrm{SiH}(4)$ & $\begin{array}{l}\text { octano, } 140{ }^{\circ} \mathrm{C} \text {, tert-dodecanotiol }{ }^{\mathrm{c}}(2 \mathrm{~mol} \%) \text {, } \\
\text { peróxido de di-tert-butila }(20 \mathrm{~mol} \%), 6 \mathrm{~h}\end{array}$ & 60 & 107 \\
\hline $\mathrm{Pr}_{3} \mathrm{SiH}(8)$ & $\begin{array}{l}\text { octano, } 140{ }^{\circ} \mathrm{C} \text {, tert-dodecanotiol }(2 \mathrm{~mol} \%) \text {, } \\
\text { peróxido de di-tert-butila }(20 \mathrm{~mol} \%), \mathrm{Ar}, 8 \mathrm{~h}\end{array}$ & 70 & 108 \\
\hline $\mathrm{PhSiH}_{3}(2)$ & AIBN (2 eq.), tolueno, refluxo, $200 \mathrm{~min}$ & $90^{\mathrm{b}}$ & 110 \\
\hline $\mathrm{PhSiH}_{3}(2)$ & $\mathrm{Bz}_{2} \mathrm{O}_{2}$ (1 eq.), tolueno, refluxo, $100 \mathrm{~min}$ & $96^{\mathrm{b}}$ & 110 \\
\hline $\mathrm{Ph}_{2} \mathrm{SiH}_{2}(2)$ & AIBN ( 2 eq.), tolueno, refluxo, $200 \mathrm{~min}$ & 92 & 110,112 \\
\hline $\mathrm{Ph}_{2} \mathrm{SiH}_{2}(2)$ & AIBN (2 eq.), dioxano, refluxo, $200 \mathrm{~min}$ & 90 & 110,112 \\
\hline $\mathrm{Ph}_{2} \mathrm{SiH}_{2}(2)$ & AIBN (2,6 eq.), dioxano, refluxo, $390 \mathrm{~min}$ & 85 & 112 \\
\hline
\end{tabular}

${ }^{\mathrm{a}}$ Atua também como solvente; ${ }^{\mathbf{b}}$ determinado por RMN de ${ }^{1} \mathrm{H}$; ${ }^{\mathbf{c}}$ mistura de isômeros com a fórmula tert- $\mathrm{C}_{12} \mathrm{H}_{25} \mathrm{SH}$, comercialmente disponível.

Tabela 2. Redução do metilxantato da diacetona glicose (72) com fosfinas.

\begin{tabular}{|c|c|c|c|}
\hline REDUTOR (eq.) & CONDIÇÕES & $(\%)$ & REF. \\
\hline$(\mathrm{EtO})_{2} \mathrm{P}(\mathrm{O}) \mathrm{H}(5,0)$ & Dioxano, $\mathrm{Bz}_{2} \mathrm{O}_{2}$ (0,4 eq.), Ar, refluxo, $1,0 \mathrm{~h}$ & $90^{\mathrm{a}}$ & 114 \\
\hline$(\mathrm{MeO})_{2} \mathrm{P}(\mathrm{O}) \mathrm{H}(5,0)$ & Dioxano, $\mathrm{Bz}_{2} \mathrm{O}_{2}$ (0,6 eq.), Ar, refluxo, $1,5 \mathrm{~h}$ & $97^{\mathrm{a}}$ & 114 \\
\hline$(\mathrm{MeO})_{2} \mathrm{P}(\mathrm{O}) \mathrm{H}(5,0)$ & Tolueno, $\mathrm{Bz}_{2} \mathrm{O}_{2}$ (1,0 eq.), Ar, refluxo, $2,5 \mathrm{~h}$ & $92^{\mathrm{a}}$ & 114 \\
\hline $\mathrm{H}_{3} \mathrm{PO}_{2}(5,0) / \mathrm{Et}_{3} \mathrm{~N}(5,0)$ & Dioxano, AIBN (0,1 eq.), refluxo, $2 \mathrm{~h}$ & $77^{\mathrm{a}}$ & 115 \\
\hline $\mathrm{H}_{3} \mathrm{PO}_{2}(5,0) / \mathrm{Et}_{3} \mathrm{~N}(5,5)$ & Dioxano, AIBN (0,4 eq.), refluxo, $40 \mathrm{~min}$ & $84^{\mathrm{a}}$ & 115,116 \\
\hline $\mathrm{H}_{3} \mathrm{PO}_{2}(5,0) / \mathrm{Et}_{3} \mathrm{~N}(11,0)$ & Dioxano, AIBN (0,5 eq.), refluxo, $45 \mathrm{~min}$ & 91 & 115,116 \\
\hline $\mathrm{H}_{3} \mathrm{PO}_{2}(5,0) / \mathrm{Et}_{3} \mathrm{~N}(11,0)$ & Dioxano, $\operatorname{AIBN}(0,4$ eq.), refluxo, $40 \mathrm{~min}$ & $91^{\mathrm{a}}$ & 116 \\
\hline$(\mathrm{n}-\mathrm{BuO})_{2} \mathrm{P}(\mathrm{O}) \mathrm{H}(1,5)$ & Dioxano, $t$-BuOO $t$-Bu $(1,0)$, refluxo, $32 \mathrm{~h}$ & 60 & 94 \\
\hline$(\mathrm{n}-\mathrm{BuO}){ }_{2} \mathrm{P}(\mathrm{O}) \mathrm{H}(3,0)$ & Dioxano, AIBN (0,75 eq.), refluxo, $24 \mathrm{~h}$ & 93 & 94 \\
\hline $\mathrm{Ph}_{2} \mathrm{P}(\mathrm{O}) \mathrm{H}(3,0)$ & Dioxano, $t$-BuOOt-Bu $(1,0)$, refluxo, $32 \mathrm{~h}$ & 80 & 117 \\
\hline $\mathrm{Ph}_{3} \mathrm{P} . \mathrm{BH}_{3}(5,0)$ & Dioxano, AIBN (0,4 eq.), refluxo, $2 \mathrm{~h}$ & $90^{\mathrm{a}}$ & 118 \\
\hline$\left(\mathrm{Me}_{3} \mathrm{SiO}\right)_{3} \mathrm{P} . \mathrm{BH}_{3}(5,0)$ & Dioxano, AIBN (0,4 eq.), refluxo, $2 \mathrm{~h}$ & 85 & 118 \\
\hline$n-\mathrm{Bu}_{3} \mathrm{P} \cdot \mathrm{BH}_{3}(2,0)$ & Dioxano, AIBN (0,3 eq.), refluxo, $1,5 \mathrm{~h}$ & 88 & 118 \\
\hline
\end{tabular}

${ }^{\text {a}}$ Determinado por RMN de ${ }^{1} \mathrm{H}$. 
do metilxantato da diacetona glicose (Tabela 2), em benzeno ou dioxana, mesmo na presença de vários haletos orgânicos, sem causar a redução destes ${ }^{118}$. Estes complexos fosfina-boranos têm as vantagens de serem menos tóxicos, mais baratos e principalmente mais seletivos do que o hidreto de tributilestanho. Dentre eles, o melhor doador de hidrogênio testado foi o complexo tributilfosfina-borano.

\section{DESOXIGENAÇÃO VIA CARBENO: A REAÇÃO DE COREY-WINTER}

A reação de Corey-Winter é outro procedimento bastante utilizado para a produção de nucleosídeos 2',3'-insaturados ${ }^{24}$. Nesta sequência, um diol vicinal, através de reação com tiocarbonildiimidazolo, é convertido em um tionocarbonato cíclico que se fragmenta, em condições apropriadas, gerarando o alceno correspondente (Esquema 22). Foi postulado que a reação de eliminação, segundo passo da síntese, ocorre via um intermediário carbeno. Este se decompõe gerando o alceno correspondente ${ }^{24-26}$. A reação de Corey-Winter usando fosfito de trimetila foi aplicada à síntese da d4U (42) ${ }^{119}$. Contudo, houve uma extensiva $N$-metilação levando à formação do composto $\mathbf{7 4}$ em $89 \%$ de rendimento. Aquecendo-se a substância $\mathbf{7 3}$ com fosfito de trietila, ao invés de fosfito de trimetila, a $160^{\circ} \mathrm{C}$, por $1 \mathrm{~h}$, ocorre olefinação sem $N^{3}$-alquilação para fornecer $75 \mathrm{em} 45 \%$ de rendimento. Este produto, após desproteção, originou o d4U (42) em $40 \%$ de rendimento (Esquema 22). Posteriormente, Dudycz ${ }^{120}$ mostrou que o problema de $N$-metilação na conversão de $\mathbf{7 3}$ a $\mathbf{7 4}$ com fosfito de trimetila, poderia ser evitado se o oxigênio fosse totalmente excluído do meio reacional. O método de Corey-Winter também foi aplicado na preparação da 2',3'-didesoxiisoguanosina e de seu análogo insaturado a partir da isoguanosina ${ }^{121}$.

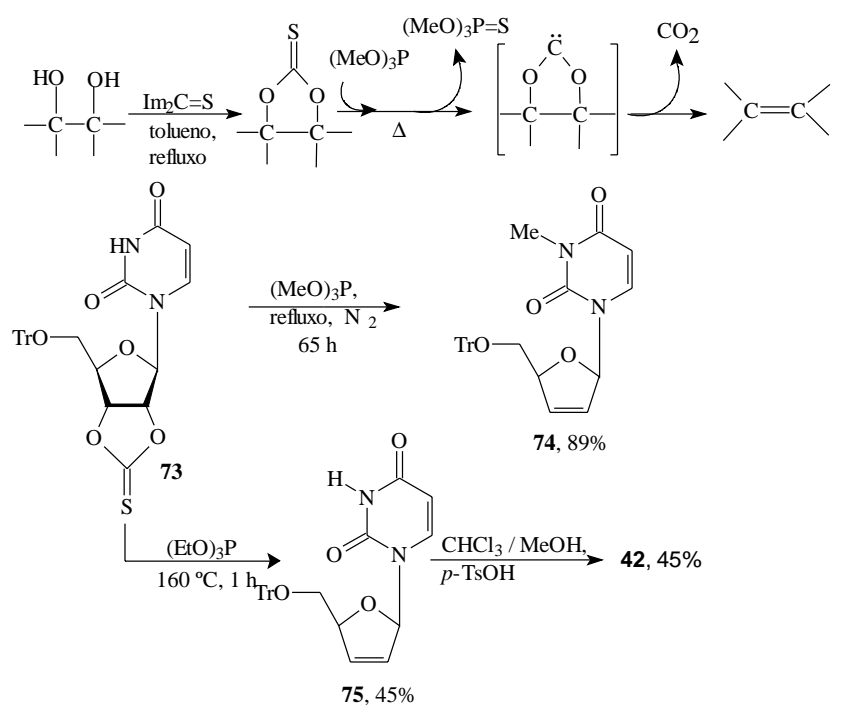

Esquema 22. Desoxigenção de dióis vicinais pelo método de Corey-Winter.

Uma importante modificação do método original foi desenvolvida por Corey e Hopkins ${ }^{27}$. Eles substituíram o tionocarbonildiimidazolo pelo tiofosgênio, na etapa de síntese do tionocarbonato cíclico, mas a principal modificação foi o uso de um derivado da diazofosfolidina em substituição aos fosfitos de trimetila e de trietila. A utilização da 1,3-dimetil-2-fenil1,3-diazofosfolidina (76) em acetonitrila como solvente permite que a reação de olefinação ocorra sob condições muito mais brandas (Esquema 23). Esta desoxigenação foi aplicada à síntese de 2',3'-didesoxinucleosídeos ${ }^{45}$. Assim, tratando-se 77 com 1,3-dimetil-2-fenil-1,3-diazafosfolidina (76) formou-se 0 derivado 2',3'-insaturado 78. Este, após hidrogenação $(85 \%)$ seguida de desproteção (96\%) levou à formação do ddC (19).

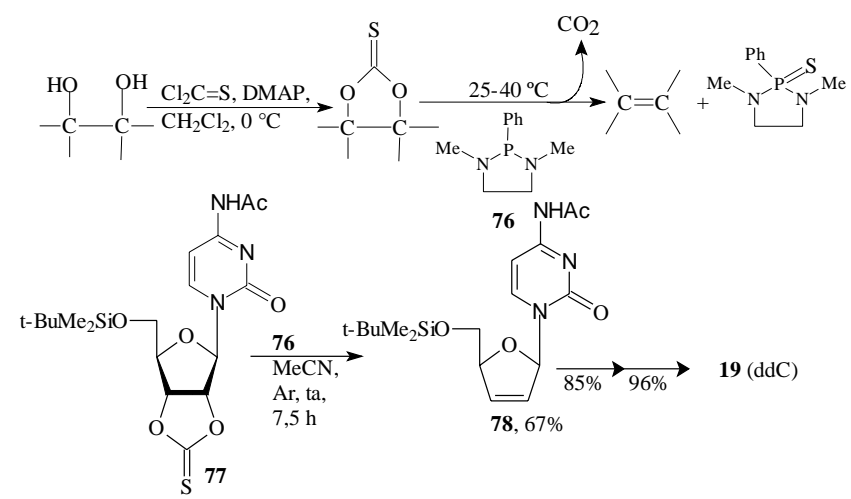

Esquema 23. Método de Corey-Hopkins para desoxigenção de tiocarbonato cíclico.

\section{REDUÇÃO COM NÍQUEL DE RANEY}

Tentativa de desoxigenação do tionocarbonato cíclico da uridina (79) ${ }^{119,122}$ com níquel de Raney, para obtenção do d4U (42) levou ao ciclo-2',3'-O-metilenonucleosídeo (80) como produto principal (Esquema 24). Entretanto, Fox e Wempen ${ }^{123}$ tiraram proveito da formação deste ciclonucleosídeo $(\mathbf{8 0})$ para preparar a 1- $\beta$-D-arabinofuranouracila $(\mathbf{8 1})$ que corresponde à série epimérica em C2' da uridina. Já a dessulfuração de tioéteres com níquel Raney funciona muito bem e foi utilizada na preparação da 2',3'-didesoxiadenosina (ddA). A desvantagem deste rota é o número de etapas para preparar o material de partida ${ }^{122}$.

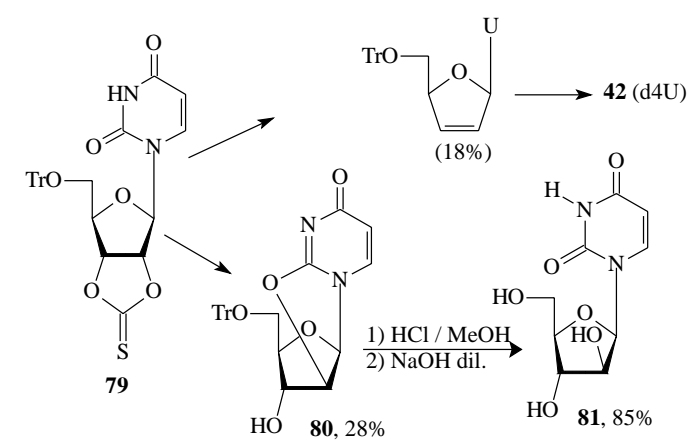

Esquema 24. Desoxigenação com níquel de Raney levando à formação de um ciclonucleosídeo.

\section{OLEFINAÇÃO DE EASTWOOD}

O método de olefinação de Eastwood ${ }^{124,125}$ se baseia na formação e decomposição de um ortoformiato cíclico de cinco membros derivado de um diol. Este fragmenta-se na presença de um catalisador ácido ou por aquecimento para produzir a olefina correspondente ${ }^{3}$. Variações deste método ${ }^{126-128}$ foram aplicadas na preparação de nucleosídeos 2',3'-insaturados. Ando e colaboradores ${ }^{129}$ aumentaram o rendimento do processo original de Eastwood usando anidrido acético como solvente na fase de aquecimento dos 2-alcoxi-1,3-dioxolanos. Através deste procedimento modificado, a uridina $(4)^{130}$ foi convertida quase que quantitativamente à 2 ', 3 '- $O$-metoximetiluridina $(\mathbf{8 2}$, Esquema 25), por tratamento com ortoformiato de trimetila na presença de uma quantidade catalítica de ácido $p$ toluenossulfônico monoidratado. O tratamento de $\mathbf{8 2}$ com uma solução de anidrido acético levou ao derivado acetilado 83 que foi posteriormente aquecido a $130{ }^{\circ} \mathrm{C}$ por três horas produzindo a 1-(5'- $O$-acetil-2',3'-didesoxi- $\beta$-D-glicero-pent-2-enofuranosil)uracila (84) em $42 \%$ de rendimento. Esta reação de olefinação é acelerada pela presença de ácidos. Porém, estes 
também promovem a decomposição do produto olefínico. O uso de bases para neutralizar o ácido acético formado como subproduto de reação torna a reação mais lenta sem contudo melhorar o rendimento ${ }^{53,130}$. Entre outros catalisadores, o melhor rendimento $(56 \%)$ é obtido com o uso de quantidades catalíticas de $\mathrm{BH}_{3} . \mathrm{NEt}_{2}$ por uma hora e meia. O uso de quantidade estequiométrica de $\mathrm{BH}_{3} \cdot \mathrm{NEt}_{2}$, ou $\mathrm{B}(\mathrm{OEt})_{3}$ e $\mathrm{BH}_{3}$.Piridina não forneceu resultados satisfatórios ${ }^{130}$.

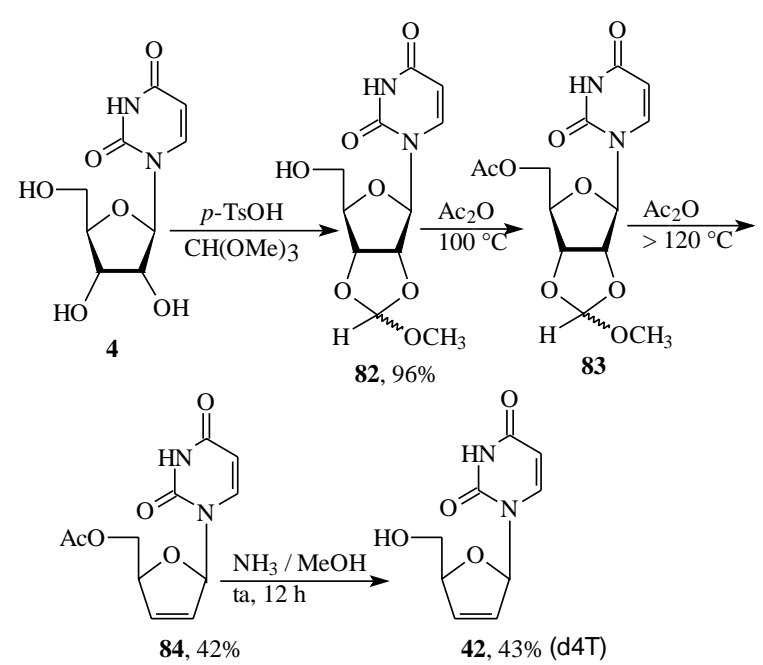

Esquema 25. Síntese do d4T pelo método de olefinação de Eastwood.

\section{ELIMINAÇÃO PROMOVIDA POR BASES}

Nos anos 60, os grupos de Horwitz ${ }^{131-136}$ e McCarthy ${ }^{137,138}$ estudaram métodos para a introdução de insaturação, em especial entre os carbonos C2'-C3' de nucleosídeos, via eliminação promovida por bases em mesilatos (ou tosilatos) e anidronucleosídeos. As combinações base-solvente mais comumente usadas foram $t$-BuOK/DMSO ${ }^{132-137} \mathrm{e} \mathrm{MeONa/} \mathrm{DMF}^{137}$. A formação da insaturação entre as posições 2' e 3' é dependente da natureza da base nitrogenada, bem como do tipo dos substituintes nas posições 3' e 5' e da configuração de C3'. Neste sentido, esta metodologia pode levar a muitos subprodutos de eliminação. Nucleosídeos pirimidinícos contendo um bom grupo de saída na posição 3' podem formar um ciclonucleosídeo resultante do ataque do oxigênio da base nitrogenada ${ }^{131-136}$. Caso o substituinte em 5' seja também um bom grupo de saída como Ms, por exemplo, há quebra da ligação do ciclonucleosídeo em $\mathrm{C}-2$ e, subseqüente ataque à posição 5' levando à formação de um derivado oxetano. Não obstante todos estes problemas, De Clercq e colaboradores ${ }^{139}$ usaram este método para a preparação da 2',3'-didesidro-2',3'didesoxiguanosina (d4G, 86) (Esquema 26). A mesma metodologia foi utilizada para a síntese de outros desidronucleosídeos, como o d4T (42), cuja etapa de eliminação ocorreu com um rendimento de $57 \%$ 140-142.

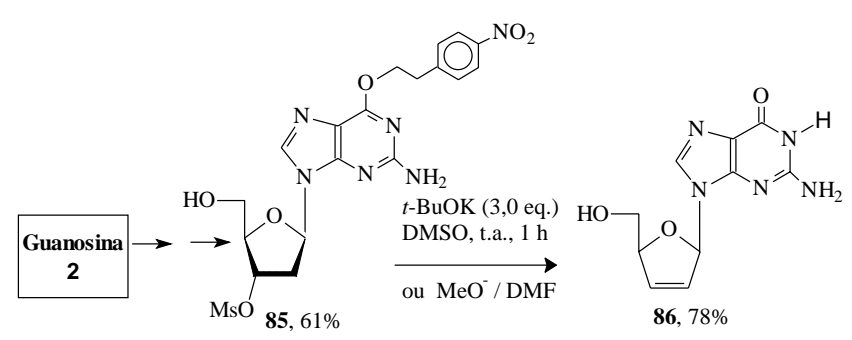

Esquema 26. Síntese do $d 4 G$ (86) por eliminação promovida por base.
Uma desvantagem do método de Horowitz é o uso de dimetilssulfóxido como solvente. No procedimento original este é removido por destilação à pressão reduzida, após neutralização. Entretanto, em reações em maior escala isto torna-se inexeqüível visto que a remoção de grandes volumes de DMSO demandaria de aquecimento prolongado, o que ocasionaria clivagem da ligação glicosídica e formação de quantidades apreciáveis da base nitrogenada como subproduto ${ }^{140}$. Um tempo de reação curto é também o desejável, uma vez que a exposição prolongada ao meio básico pode levar à ruptura da ligação glicosídica. Tentativas de substituição do DMSO por outros solventes apresentaram resultados insatisfatórios. O THF mostrou-se o mais conveniente em pequena escala, mas devido à baixa solubilidade do intermediário neste solvente, a reação não se completa. $\mathrm{O}$ uso de excesso de base visando completar a reação levou à formação de quantidade substancial da base nitrogenada como subproduto. Outros solventes como DMF ou DME tornam a reação mais lenta ${ }^{140}$. Na obtenção do d4T (42), Mansuri e colaboradores não encontraram uma combinação base-solvente que produzisse uma reação mais limpa e rápida do que $t$-BuOK/DMSO ${ }^{140}$. No isolamento do produto, o melhor procedimento constituiu-se na separação por filtração do sal de d4T(42), precipitado no meio reacional pela adição de tolueno, seguida de redissolução do precipitado em água, neutralização com ácido clorídrico e de precipitação do produto por adição de solução aquosa saturada de cloreto de potássio. O sólido obtido foi dissolvido em acetona, e o solvente foi filtrado e evaporado levando ao d4T (42).

\section{OUTROS MÉTODOS}

Além dos métodos discutidos nas seções precedentes, vários outros foram empregados na preparação de 2',3'-didesidro2',3'-didesoxinucleosídeos e 2',3'-didesoxinucleosídeos. Tiiranos ou epissulfetos (87) podem ser também dessulfurados com o uso de fosfitos de trialquila, trifenilfosfina ou hidreto de tributilestanho gerando os alcenos (Esquema 27) ${ }^{144,145}$. Há vários métodos para a preparação de tiiranos, mas os mais eficientes empregam epóxidos como matérias-primas e tiouréia ou tiocianato de amônio como fonte de enxofre ${ }^{144}$. Variações desta reação têm surgido mais recentemente, usando-se diversos catalisadores como nitrato cérico amoniacal (CAN) ${ }^{146}$, $\mathrm{TiO}(\mathrm{TFA})_{2}$ ou $\mathrm{TiCl}_{3}(\mathrm{OTf})^{147}$ e tricloreto de bismuto ${ }^{148}$. A dessulfuração de tiiranos utilizando-se hidreto de tributilestanho produz alcenos em bons rendimentos em geral $^{32}$.

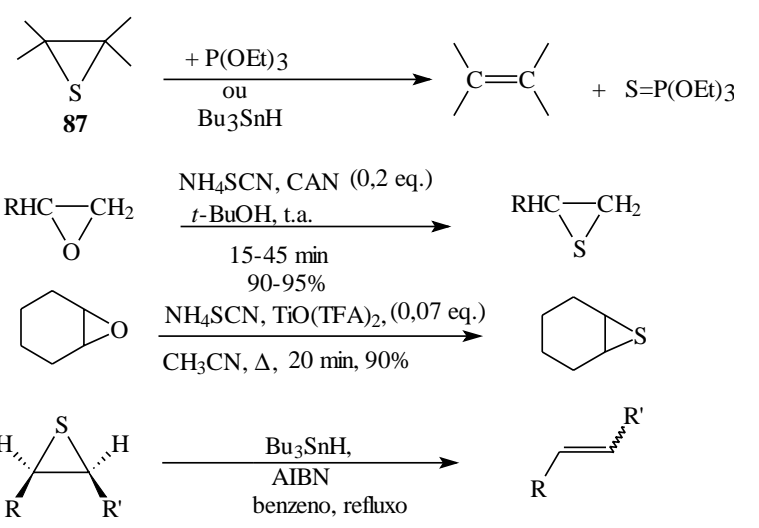

Esquema 27. Alguns métodos catalíticos de preparação de epissulfetos.

O diol 88, um seleno derivado, foi convertido ao alceno $(\mathbf{9 0})^{149}$, através da redução do seu dimesilato $(\mathbf{8 9})$ por tratamento com naftalenídeo de sódio (naftaleno + sódio metálico) (Esquema 28). 


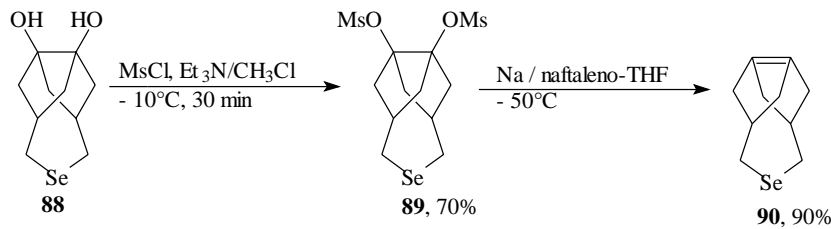

Esquema 28. Uso de naftalenídeo de sódio na síntese de um alceno a partir de um diol.

Este mesmo método foi usado ${ }^{150}$ para a síntese de 2',3'didesidro-2',3'-didesoxinucleosídeos a partir de 2',3'-di- $O$-mesilD-ribonucleosídeos com a hidroxila $5^{\prime}$ protegida, como exemplificado para os derivados da adenosina (91, Esquema 29). Clive e colaboradores ${ }^{151}$ desenvolveram um novo método de conversão de derivados 2',3'-di- $O$-mesilados-5' $-O$-protegidos através do uso de teluretos e selenetos de sódio ou lítio. Aplicando este procedimento, os autores prepararam o nucleosídeo olefínico 94, a partir do derivado 2',3'-dimesilado (93) usando teluretos de sódio e lítio em diferentes solventes (Esquema 29). $\mathrm{O}$ uso de selenetos de sódio ou lítio levou ao produto 94 mas com rendimentos inferiores, tendo sido obtido o melhor resultado com o fenilseleneto de lítio ${ }^{152}$. Cerca de $50 \%$ do telúrio elementar usado na preparação dos sais pode ser recuperado da mistura reacional ao término da reação (Esquema 29).
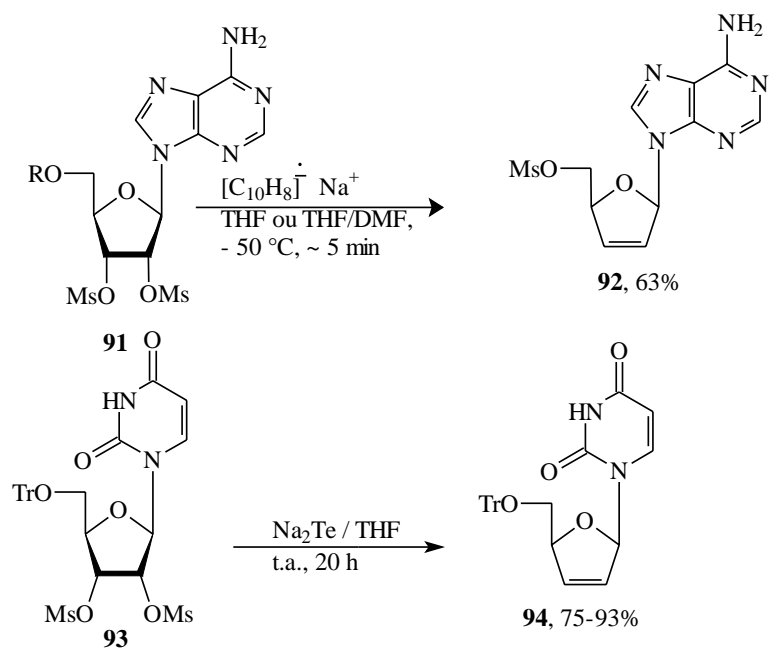

Esquema 29. Eliminação redutiva de dimesilato com naftalinídeo de sódio.

Mais recentemente ${ }^{153}$, derivados 2',3'-di- $O$-mesil-5'- $O$ formilados (95 e 96) foram convertidos diretamente a $2^{\prime}, 3$ 'didesoxinucleosídeos (ddA, 97; ddI, 18) por hidrogenação catalítica em meio básico, como mostra o Esquema 30. Entretanto, esta metodologia tem a desvantagem do uso de pressões elevadas para promover a hidrogenólise dos grupos mesilatos.
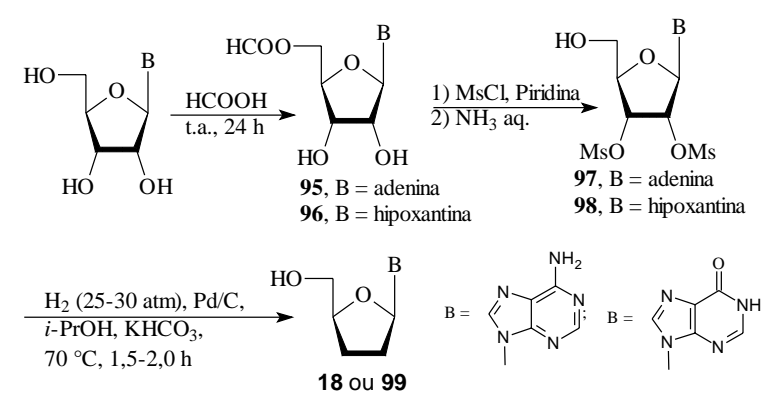

Esquema 30. Hidrogenação catalítica de derivados 2',3'-dimesilatos.
Sulfatos cíclicos e também sulfitos ${ }^{150}$ são usados como substratos reativos para várias reações de substituição nucleofílica ${ }^{14,38,154,155}$. De forma similar aos epóxidos, sulfatos cíclicos podem ser abertos por ataque de uma variedade de nucleófilos aos seus átomos de carbono. Contudo, ao contrário dos oxiranos, a abertura do sulfato cíclico envolve a geração de um monoéster sulfato, permitindo uma transformação posterior. O sulfato gerado é um bom grupo de saída e pode ser subsequientemente substituído por um nucleófilo, permitindo que ambas as hidroxilas do diol original sejam substituídas. Como o $\mathrm{SO}_{4}=$ é um grupo de saída muito menos eficiente do que $\mathrm{ROSO}_{3}{ }^{-}$, a segunda substituição é melhor efetuada se ocorrer de modo intramolecular ${ }^{14}$. Tais propriedades tornam os sulfatos cíclicos sinteticamente muito versáteis, inclusive permitindo a síntese de olefinas de modo direto ${ }^{37,39-41}$, ou indireto ${ }^{14}$.

Os métodos de preparação de sulfatos cíclicos incluem o tratamento de um diol com cloreto de sulfurila ou sulfato de diimidazolo ${ }^{154,155}$. Outra alternativa é a oxidação de sulfitos cíclicos, facilmente obtidos pela reação de cloreto de tionila com um diol seguida por oxidação com permanganato de potássio aquoso/diclorometano ${ }^{154,155}, \mathrm{RuO}_{4}{ }^{156,157}$ ou $\mathrm{NaIO}_{4} / \mathrm{RuCl}_{3} \cdot \mathrm{H}_{2} \mathrm{O}{ }^{38}$.

A eliminação redutiva destes sulfatos cíclicos pode ser realizada por uma grande variedade de reagentes. Dittmer e colaboradores ${ }^{40}$ utilizaram nesta reação o íon telureto gerado in situ, em condições brandas $\left(0{ }^{\circ} \mathrm{C} \rightarrow\right.$ temperatura ambiente $)$. Um exemplo desta reação está na transformação do sulfato cíclico (100) no alceno (101) (Esquema 31). Naftalenídeo de sódio também pode ser usado para transformação de sulfatos cíclicos de dióis vicinais em olefinas ${ }^{41}$. Naftalenídeo de sódio também foi empregado para a eliminação redutiva de fosfato 2',3'-cíclico (102), mas com baixo rendimento ${ }^{150}$.

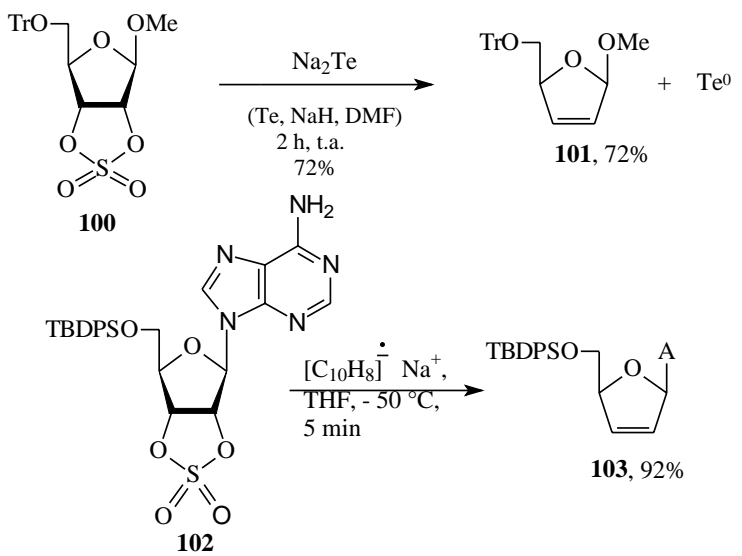

Esquema 31. Utilização do íon telureto e de naftalinídeo de sódio na eliminação redutiva de sulfato e de fosfato cíclicos.

Uma reação de transferência de elétrons fotossensibilizada foi aplicada à desoxigenação seletiva das hidroxilas secundárias do derivado benzoilado da uridina (104) para originar, diretamente, o 2',3'-didesoxinucleosídeo correspondente (105, Esquema 32$)^{159}$. Fotólises de ésteres para desoxigenação de álcoois em HMPA-água como solvente, embora não sendo seletivas, já haviam sido relatadas anteriormente tendo seu mecanismo amplamente estudado ${ }^{160-163}$. Os ésteres $m$-(trifluorometil) benzoatos ${ }^{159,163}$ são mais fácil e rapidamente desoxigenados do que os benzoatos. Os benzoatos, entretanto, são mais disponíveis e baratos. A desoxigenação preferencial de $m$-(trifluorometil)benzoato frente ao benzoato está exemplificada na transformação de 106 em 107 (Esquema 32).

É importante ainda ressaltar que o método de formação de ligação dupla carbono-carbono através do rearranjo de selenóxidos também foi aplicado na síntese de nucleosídeos 2',3'-insaturados a partir de desoxinucleosídeos (Esquema 
$33)^{164}$ conforme exemplificado para as transformações de 108a,b em 109a,b.

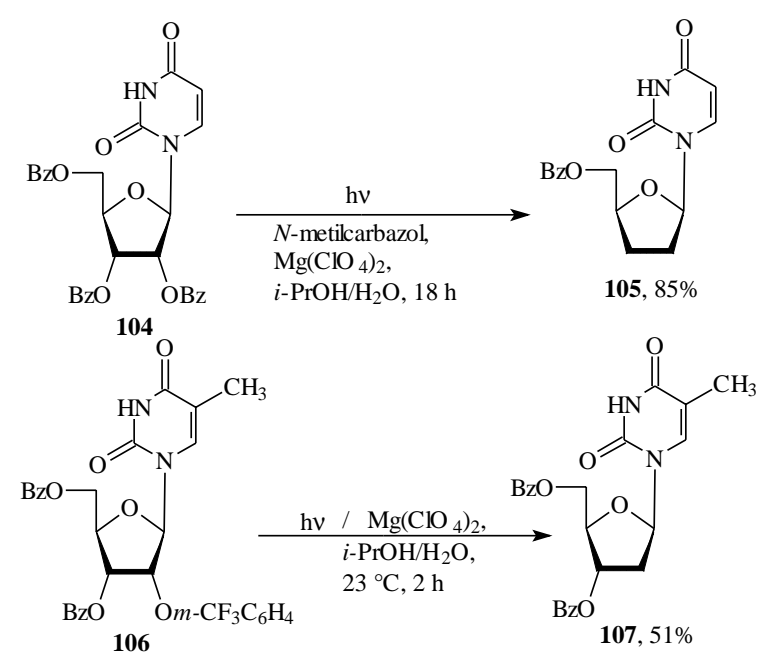

Esquema 32. Desoxigenação fotoquímica de ésteres.

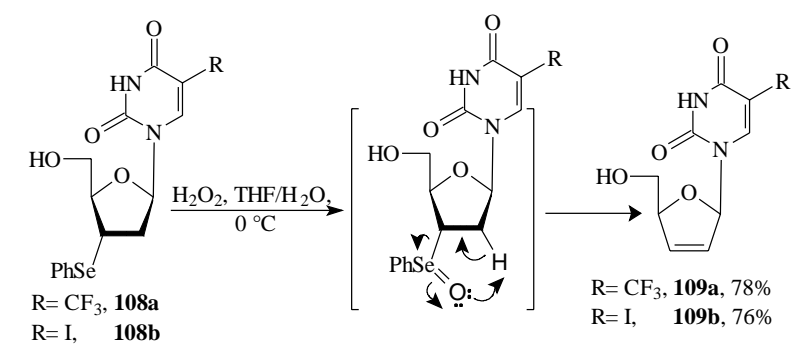

Esquema 33. Síntese de nucleosídeos 2',3'-insaturados via rearranjo de selenóxidos de desoxinucleosídeos

\section{CONCLUSÕES}

Durante a última década houve um aumento considerável no volume de pesquisas dedicadas à busca de agentes quimioterápicos para o tratamento de infecções virais. ${ }^{165-167}$ Apesar desta ampliação, um número limitado de novos agentes antivirais vem sendo utilizado clinicamente. $\mathrm{O}$ íntimo relacionamento que existe entre a multiplicação do vírus e as células do hospedeiro faz com que os agentes antivirais, em sua grande maioria, não sejam tão seletivos, mas sim igualmente tóxicos ao vírus e ao hospedeiro. Neste sentido, a síntese de novos antivirais continua atraindo a atenção da comunidade científica, e os métodos de desoxigenação de nucleosídeos ocupam atualmente as fronteiras nesta área da química sintética voltada à preparação de substâncias com possibilidades de aplicações farmacêuticas.

O emprego do nucleosídeo derivatizado nas posições 2',3' para a produção de desoxinucleosídeos é a abordagem mais abrangente, pois permite um largo espectro de reações de eliminação redutiva. Porém, mais pesquisas precisam ser realizadas de modo a tornar viável o uso de nucleosídeos não derivatizados nestas posições, ou seja o emprego do próprio diol nas reações de desoxigenações. Isto, além de reduzir o número de etapas da rota sintética, irá tornar os desoxinucleosídeos mais acessíveis e economicamente atrativos. De qualquer forma, em todas essas abordagens, o princípio do controle da regiosseletividade é ponto chave, evitando reações competitivas, como a eliminação da base nitrogenada.

Finalmente, deve-se ressaltar que a despeito das dificuldades sintéticas um enorme progresso foi alcançado na síntese industrial deste tipo de substâncias, haja vista que para o tratamento da AIDS se dispõe atualmente de alguns novos agentes antivirais derivados de desoxinucleosídeos.

Aos pesquisadores que desenvolveram todos estes métodos descritos nesta revisão, muitos destes utilizados industrialmente, devemos prestar a nossa homenagem.

\section{AGRADECIMENTOS}

Os autores VFF e MCBVS agradecem ao CNPq pelas bolsas de produtividade e ao apoio financeiro de PADCT, CNPq, CAPES e FAPERJ aos projetos do nosso grupo de pesquisa em nucleosídeos. MCS agradece a CAPES pela bolsa de mestrado concedida e ao Programa de Pós-Graduação em Química Orgânica da UFF.

\section{REFERÊNCIAS}

1. a. Perigaud, C.; Gosselin, G.; Imbach, J. L.; Nucleosides \& Nucleotides 1992, 11, 903. b. Levene, P. A.; Jacobs, W. A.; Chem. Ber. 1909, 42, 2474. c. Mizuno, Y.; The Organic Chemistry of Nucleic Acids; série Studies in Organic Chemistry vol. 24; Elsevier; Amsterdam 1986; p 19.

2. a. Collins, P.; Ferrier, R.; Monossacharides - Their Chemistry and Their Roles in Natural Products; John Wiley \& Sons; London 1995. b. Isono, K; J. Antibiot. 1988, 16, 1711. c. Montgomery, J. A.; Antiviral Res. 1989, $12,113$.

3. Huryn, D. M.; Okabe, M.; Chem. Rev. 1992, 92, 1745.

4. Mansuri, M.. M.; Hitchcock, M. J.; Chemtech 1992, 564.

5. De Clercq, E.; Clin. Microb. Rev. 1995, 8, 200.

6. a. Dueholm, K. L.; Pedersen, E. B.; Synthesis 1992, 1. b. Wilson, L. J.; Hager, M. W.; El-Kattan, Y. A.; Liotta, D. C.; Synthesis 1995, 1465.

7. a. O termo base nitrogenada está sendo utilizado para representar os heterociclos que fazem parte dos nucleosídeos. b. Niedballa, U.; Vorbrüggen, H.; J. Org. Chem. 1974, 39, 3654. c. Niedballa, U.; Vorbrüggen, H.; J. Org. Chem. 1974, 39, 3660. d. Niedballa, U.; Vorbrüggen, H.; J. Org. Chem. 1974, 39, 3664. (e) Niedballa, U.; Vorbrüggen, H.; J. Org. Chem. 1974, 39, 3668. f. Niedballa, U.; Vorbrüggen, H.; J. Org. Chem. 1974, 39, 3672. g. Niedballa, U.; Vorbrüggen, H., J. Org. Chem. 1976, 41, 2084.

8. a. Vorbrüggen, H.; Acta Biochemica Polonica 1996, 43, 25. b. Vorbrüggen, H.; Höfle, G.; Chem. Ber. 1981, 114, 1256.

9. Aldrich Chem. Company, Inc (b-D-ribofuranose-1-acetate2,3,5-tribenzoate, código 15, 901-8 [ 10g, US\$ 46.35]; Catalog Handbook of Fine Chemicals 1994-1995, 1237.

10. Bennua-Skalmowski, B.; Krolikiewicz, K.; Vorbrüggen, H.; Tetrahedron Lett. 1995, 36, 7845.

11. Nagai, M.; Matsutani, T.; Mukaiyama, T.; Heterocycles 1996, $42,57$.

12. da Matta, A. D.; Bernardino, A. M. R.; Romeiro, G. A.; de Oliveira, M. R. P.; de Souza, M. C. B. V.; Ferreira, V. F.; Nucleosides \& Nucleotides 1996, 15, 889.

13. da Matta, A. D.; dos Santos, C. V. B; Pereira, H. de S.; Frugulhetti, I. C. de P. P.; de Oliveira, M. R. P.; de Souza, M. C. B. V.; Moussatché, N.; Ferreira, V. F.; Heteroatom. Chem. 1999,10, 197.

14. Calvo-Flores, F. G.; García-Mendoza, P.; HernandezMateo, F.; Isac-García, J.; Santoyo-González, F.; J. Org. Chem. 1977, 62, 3944 e referências nela citadas.

15. Sharpless, K. B.; Flood, T. C.; J. Chem. Soc., Chem. Commun. 1977, 7, 370.

16. McMurry, J. E.; Fleming, M. P.; J. Org. Chem. 1976, 41,896

17. McMurry, J. E.; Acc. Chem. Res. 1983, 16, 405.

18. Sarma, J. C.; Barua, N. C.; Sharma, R. P.; Barua, J. N.; Tetrahedron 1983, 39, 2843. 
19. Garegg, P.; Samuelsson, B.; Synthesis 1979, 469.

20. Tanaka, S.; Yasuda, A.; Yamamoto, H.; Nozaki, H.; J. Am. Chem. Soc. 1975, 97, 3252.

21. Cook, G. K.; Andrews, M. A.; J. Am.Chem. Soc. 1996, $118,9448$.

22. Albano, E.; Horton, D.; Tsuchiya, T.; Carbohydr. Res. 1966, 2, 349; Chem. Abstr. 1967, 66, 18830t.

23. Barret, A. G. M.; Barton, D. H. R.; Bielski, R.; J. Chem. Soc., Perkin Trans.1, 1979, 2378.

24. Corey, E. J.; Winter, R. A. E.; J. Am. Chem. Soc. 1963, $85,2677$.

25. Corey, E. J.; Carey, F. A.; Winter, R. A. E.; J. Am. Chem. Soc. 1965, 87, 934.

26. Horton, D.; Tindall Jr., C. G.; J. Org. Chem. 1970, 35, 3558.

27. Corey, E. J.; Hopkins, P. B.; Tetrahedron Lett. 1982, 23,1979 .

28. Wittig, G.; Haag, W.; Chem. Ber. 1955, 88, 1654.

29. Uenishi, J.; Kubo, Y.; Tetrahedron Lett. 1994, 35, 6697.

30. Neureiter N. P.; Bordwell, F. G.; J. Am. Chem. Soc. 1959, $81,578$.

31. Sonnet, P. E.; Tetrahedron 1980, 36, 557.

32. Izraelewicz, M. H.; Nur, M.; Spring, R. T.; Turos, E.; J. Org. Chem. 1995, 60, 470.

33. Schuetz, R. D.; Jacobs, L.; J. Org. Chem. 1961, 26, 3467.

34. Trost, B. M.; Ziman, S. D.; J. Org. Chem. 1973, 38, 932.

35. Horton, D; Thomson, J. K.; Tindall, C. G.; Methods Carbohyd. Chem. 1994, 6, 297.

36. Marshall, J. A.; Lewellyn, M. E.; J. Org. Chem. 1977, 42,1311

37. Nonaka, T.; Kihara, S.; Fuchigami, T.; Baiezer, M. M.; Bull. Chem. Soc. Jpn 1984, 57, 3160.

38. Gao, Y.; Sharpless, K. B.; J. Am. Chem. Soc. 1988 , 110, 7538

39. Beels, C. M. D.; Coleman, M. J.; Taylor, R. J. K.; Synlett 1990, 479.

40. Chao, B.; McNulty, K. C.; Dittmer, D.; Tetrahedron Lett. 1995, 36, 7209 .

41. Jang, D. O.; Joo, Y. H.; Cho, D. H.; Synth. Commun. 1997, 27, 2379 .

42. Luzzio, F. A.; Menes, M. E.; J. Org. Chem. 1994, 59, 7267.

43. Liu, Z.; Classon, B.; Samuelsson, B.; J. Org. Chem. 1990, $55,4273$.

44. Classon, B.; Liu, Z.; Samuelsson, B.; J. Org. Chem. 1988, 53,6126

45. Manchand, P. S.; Belica, P. S.; Holman, M. J.; Huang, T.N.; Maehr, H.; Tam, S. Y.-K.; Yang, R. T.; J. Org. Chem. 1992, 57, 3473.

46. Mattocks, A. R.; J. Chem. Soc. 1964, 1918.

47. Greenberg, S.; Moffatt, J. G.; J. Am. Chem. Soc. 1973 , $95,4016$.

48. Russell, A. F.; Greenberg, S.; Moffatt, J. G.; J. Am. Chem. Soc. 1973, 95, 4025.

49. a. Marumoto, R.; Honjo, M.; Chem. Pharm. Bull. 1974, 22, 128. b. Brokes, J.; Hrebabecky, H.; Beranek, J.; Coll. Czech. Chem. Commun. 1979, 44, 439.

50. Huang, H;. Chu, C. K.; Synth. Commun. 1990, 20, 1039.

51. Kondo, K.; Adachi, T.; Inoue, I.; J. Org. Chem. 1977, $42,3967$.

52. Robins, M. J.; Hansske, F.; Low, N. H.; Park, J. I.; Tetrahedron Lett. 1984, 25, 367.

53. Mansuri, M. M.; Starrett, J. E., Jr.; Wos, J. A.; Tortoloni, D. R.; Brodfuehrer, P. R.; Howell, H. G.; Martin, J. C.; J. Org. Chem. 1989, 54, 4780.

54. Shiragami, H.; Ineyama, T.; Uchida, Y.; Izawa, K.; Nucleosides \& Nucleotides 1996, 15, 47.

55. Robins, M. J.; Mengel, R.; Jones, R. A.; J. Am. Chem. Soc. 1973, 95, 4074.

56. Robins, M. J.; Mengel, R.; Jones, R. A.; Yves-Fouron; $J$. Am. Chem. Soc. 1976, 98, 8204.
57. Robins, M. J.; Jones, R. A.; M, R.; J. Am. Chem. Soc. 1976, 98, 8213.

58. Mengel, S.; Seifert, J.-M.; Tetrahedron Lett. 1977, 48, 4203.

59. a. Bhat, K. S.; Rao, A. S.; Indian J. Chem. 1983, 22B, 678. b. Reichman, U.; Chu, C. K.; Hollenberg, D. H.; Watanabe, K. A.; Fox, J. J.; Synthesis 1976, 533.

60. Chen, B.-C.; Quinlan, S. L.; Reid, J. G.; Spector, R. H.; Tetrahedron Lett. 1998, 39, 729.

61. Jain, T. C.; Jenkins, I. D.; Russell, A. F.; Verheyden, J. P. H.; Moffatt, J. G.; J. Org. Chem. 1974, 39, 30.

62. Kochi, J. K.; Singleton, D. M.; Andrews, L. J.; Tetrahedron 1968, 24, 3503.

63. Adachi, T.; Iwasaki, T.; Inoue, I.; Miyoshi, M.; J. Org. Chem. 1979, 44, 1404.

64. Classon, B. C.; Garegg, P. J.; Samuelsson, B; Acta Chem. Scand. 1982, B 36, 251.

65. Mansuri, M. M.; Starret, J. E.; Ghazzoulli, I.; Hitchcock, M. J. M.; Sterzycki, R. Z.; Brankovan, V.; Lin, T. S.; August, E. M.; Prusoff, W. H.; Sommadossi, J. P.; Martin, J. C.; J. Med. Chem. 1989, 32, 461.

66. Robins, J. M.; Wilson, J. S.; Madej, D.; Low, N. H.; Hansske, F.; Wnuk, S. F; J. Org. Chem.1995, 60, 7902.

67. Hidetoshi, Y.; Eiji, K.; Shuji, I.; Hiroyuki, Y.; Kunimutsu, M.; JP 02-91096 (patente); Chem. Abstr. 1990, 113, 32718b.

68. Dorland, E.; Serafinowski, P.; Synthesis 1992, 477.

69. a. Norman, D. G.; Reese, C.; Synthesis 1983, 304. b. Talekar, R. R.; Coe, P. L.; Walker, R. T.; Synthesis 1993, 303.

70. Dillon, J. L.; Synth. Commun. 1997, 27, 4367.

71. da Matta, A. D.; Dissertação de Mestrado, Instituto de Química, Universidade Federal Fluminense 1998.

72. Amino, Y.; Iwagami, H.; Chem. Pharm. Bull. 1991, 39, 622.

73. Cristol, S. J.; Rademacher, L. E.; J. Am. Chem. Soc. 1959, $81,1600$.

74. Chen, B.-C.; Quinlan, S. L.; Stark, D. R.; Reid, J. G.; Audia, V. H.; George, J. G.; Eisenreich, E.; Brundidge, S. P.; Racha, S.; Spector, R. H.; Tetrahedron Lett. 1995, 36, 7957.

75. Furukawa, Y.; Yoshioka, Y.; Imai, K.-I.; Honjo, M.; Chem. Pharm. Bull. 1970, 18, 554.

76. Shiragami, H.; Irie, Y.; Iwagami, T.; JP 02-117689 (patente); Chem. Abstr. 1990, 113, 132720w.

77. Shiragami, H.; Amino, Y.; Honda, Y.; Arai, M.; Tanaka, Y., Iwagami, H.; Yukawa, T.; Izawa, K.; Nucleosides \& Nucleotides, 1996, 15, 31.

78. Shiragami, H.; Tanaka, Y.; Uchida, Y.; Iwagami, H.; Izawa, K.; Yukawa, T.; Nucleosides \& Nucleotides 1992, 11,391

79. Robins, M. J.; Mengel, R.; Jones, R. A.; J. Am. Chem. Soc. 1973, 95, 4074.

80. Pfitzner, K. E.; Moffatt, J. G.; J. Org. Chem. 1964, 29, 1508.

81. Jain, T. C.; Russell, A. F.; Moffatt, J. G.; J. Org. Chem. 1973, 38, 3179.

82. Corey, E. J.; Suggs, J. W.; J. Org. Chem. 1975, 40, 2554.

83. Barton, D. H. R.; McCombie, S. W.; J. Chem. Soc., Perkin 1, 1975, 574.

84. Hartwig, W.; Tetrahedron 1983, 39, 2609 e referências nela citadas.

85. Barton, D. H. R.; Hartwig, W.; Motherwell, R. S. H.; Motherwell, W. B.; Stange, A.; Tetrahedron Lett. 1982, 23, 2019.

86. Barton, D. H. R.; Hartwig, W.; Motherwell, W. B.; J. Chem. Soc. Chem. Commun. 1982, 447.

87. Robins, M. J.; Wilson, J. S.; Hansske, F.; J. Am. Chem. Soc. 1983, 105, 4059.

88. Prisbe, E. J.; Martin, J. C.; Synth. Commun. 1985, 15, 401. 89. Hiebl, J.; Zbiral, E.; Tetrahedron Lett. 1990, 31, 4007.

90. Barton, D. H. R.; Jaszberenyi, J. Cs.;Tetrahedron Lett. 1989, 30, 2619.

91. Barton, D. H. R.; Jang, D. O.; Jaszberenyi, J. Cs.; Tetrahedron Lett. 1990, 31, 4681.

92. Nishiyama, K.; Oba, M.; Tetrahedron Lett. 1993, 34, 3745. 
93. Barton, D. H. R.; Parekh, S. I.; Tajbakhsh, M.; Theodorakis, E. A.; Tse, C.-L.; Tetrahedron 1994, 50, 639. 94. Jang, D. O.; Cho, D. H.; Barton, D. H. R.; Synlett 1998, 39. 95. Barrett, A. G. M.; Barton, D. H. R.; Bielski, R.; McCombie, S. W.; J. Chem. Soc. Chem. Commun.1977, 866.

96. Kim, C.-H.; Marquez, V. E.; Broder, S.; Mitsuya, H.; Driscoll, J. S.; J. Med. Chem. 1987, 30, 862.

97. Rosowsky, A.; Solan, V. C.; Sodroski, J. G.; Ruprecht, R. M.; J. Med. Chem. 1989, 32, 1135.

98. Barton, D. H. R.; Subramanian, R.; J. Chem. Soc., Chem. Commun. 1976, 867.

99. Barton, D. H. R.; Subramanian, R.; J. Chem. Soc., Perkin Trans. 1 1977, 1718.

100. Lin, T.-S.; Yang, J.-H.; Liu, M.-C.; Zhu, J.-L.; Tetrahedron Lett. 1990, 31, 3829.

101. Serafinowski, P.; Synthesis 1990, 411.

102. Seela, F.; Muth, H.-P.; Bindig, U.; Synthesis, 1988, 670

103. Sekine, M.; Nakanishi, T.; J. Org. Chem. 1990, 55, 924.

104. Lopez, R. M.; Hays, D. S.; Fu, G. C.; J. Am. Chem. Soc. 1997, 119, 6949.

105. Barton, D. H.; Jang, D. O.; Jaszberenyi, J. Cs.; Tetrahedron Lett. 1991, 32, 7187.

106. Allen, R. P.; Roberts, B. P.; Willis, C. R.; J. Chem. Soc. Chem. Commun. 1989, 1387.

107. Kirwan, J. N.; Roberts, B. P.; Willis, C. R.; Tetrahedron Lett. 1990, 31, 5093.

108. Cole, S. J.; Kirwan, J. N.; Roberts, B. P.; Willis, C. R.; J. Chem. Soc. Perkin Trans. 1, 1991, 103.

109. Barton, D. H. R.; Jang, D. O.; Jaszberenyi, Cs. J.; Tetrahedron Lett. 1992, 33, 6629.

110. Barton, D. H. R.; Jang, D. O.; Jaszberenyi, Cs. J.; Synlett $1991,435$.

111. Barton, D. H. R.; Jang, D. O.; Jaszberenyi, Cs. J.; Tetrahedron Lett. 1991, 32, 2569.

112. Barton, D. H. R.; Jang, D. O.; Jaszberenyi, Cs. J.; Tetrahedron 1993, 49, 7193.

113. Lesage, M.; Simões, J. A. M.; Griller, D.; J. Org. Chem. 1990, 55, 5413 .

114. Barton, D. H. R.; Jang, D. O.; Jaszberenyi, Cs. J.; Tetrahedron Lett. 1992, 33, 2311.

115. Barton, D. H. R.; Jang, D. O.; Jaszberenyi, Cs. J.; J. Org. Chem. 1993, 58, 6838 .

116. Barton, D. H. R.; Jang, D. O.; Jaszberenyi, Cs. J.; Tetrahedron Lett. 1992, 33, 5709.

117. Jang, D. O.; Cho, D. H.; Kim, J.; Synth. Commun 1998, 28,3559 .

118. Barton, D. H. R.; Jacob, M., Tetrahedron Lett. 1998, 39, 1331.

119. Ruyle, W. V.; Shen, T. Y.; Patchett, A. A.; J. Org. Chem. 1965, 30, 4353.

120. Dudycz, L. W.; Nucleosides \& Nucleotides 1989, 8, 35 Chem. Abstr. 1989, 111, 39790t.

121. Chen, C.-S.; ChernN, J.-W.; Nucleosides \& Nucleotides 1996, 15, 1253.

122. Tong G. L.; Lee, W. W.; Goodman, L.; J. Org. Chem. $1965,30,2854$

123. Fox, J. J.; Wempen, T.; Tetrahedron Lett. 1965, 11, 643.

124. Crank, G.; Eastwood, F. W.; Aust. J. Chem. 1964, 17, 1392; Chem. Abstr. 1964, 62, 7626g.

125. Josan, J. S.; Eastwood, F. W.; Aust. J. Chem. 1968, 21 , 2013; Chem. Abstr. 1968, 69, 86862s.

126. Wang, P. Y.; Gullen, B; Newton, M. G.; Cheng, Y. C.; Schinazi, R. F.; Chu, C. K.; J. Med. Chem. 1999, 42, 3390.

127. Eastwood, F.W.; Harrington, K. J.; Josan, J. S.; Pura, J. L.; Tetrahedron Lett. 1970, 60, 5223.

128. Hanessian, S.; Bargiotti, A.; LaRue, M.; Tetrahedron Lett. 1978, 8, 737

129. Ando, M.; Ohhara, H.; Takase, K.; Chem. Lett. 1986, 6, 879.

130. Shiragami, H.; Irie, Y.; Shirae, H.; Yodozeki, K.; Yasuda, N.; J. Org. Chem. 1988, 53, 5170.
131. Horwitz, J. P.; Chua, J.; Urbanski, J. A.; Noel, M.; J. Org. Chem. 1963, 28, 942.

132. Horwitz, J. P.; Chua, J.; Da Rooge, M. A.; Noel, M.; Tetrahedron Lett. 1964, 38, 2725.

133. Horwitz, J. P.; Chua, J.; Klundt, I. L.; Da Rooge, M. A.; Noel, M.; J. Am. Chem. Soc. 1964, 86, 1896.

134. Horwitz, J. P.; Chua, J.; Da Rooge, M. A.; Noel, M.; Klundt, I. L.; J. Org. Chem. 1966, 31, 205.

135. Horwitz, J. P.; Chua, J.; Noel, M.; Donatti, J. T.; J. Org. Chem. 1967, 32, 8178.

136. Horwitz J. P.; Chua, J.; Noel, M.; Tetrahedron Lett. 1966, 13, 1343.

137. McCarthy, J. R., Jr.; Robins, M. J.; Towsend, L. B.; Robins, R. K.; J. Am. Chem. Soc. 1966, 88, 1549.

138. McCarthy, J. R.; Robins, R. K.; Robins, M. J.; J. Am. Chem. Soc.1968, 90, 4993.

139. Herdewijn, P.; Balzarini, J.; Baba, M.; Pauwels, R.; Van Aerschot, A.; Janssen, G.; De Clercq, E.; J. Med. Chem. 1988, 31, 2040.

140. Mansuri, M. M.; Starrett, J. E.; Ghazzoulli, I.; Hitchcock, M. J. M.; Sterzycki, R. Z.; Brankovan, V.; Lin, T.-S.; August, E. M.; Prusoff, W. H.; Sommadossi, J.-P.; Martin, J. C. ; J. Med. Chem. 1989, 32, 461 .

141. Reese, C. B.; Varaprasad, C. V. N.; J. Chem. Soc. Perkin Trans. 1 1994, 189.

142. Lin, T.-S.; Luo, M.-Z.; Liu, M.-C.; Zhu, Y.-L.; Gullen, E.; Dutschman, G. E.; Cheng, Y.-C.; J. Med. Chem. 1996, 39, 1757.

143. Robins, M. J.; Robins, R. K.; J. Am. Chem. Soc.1964, 86, 3585.

144. Gilchrist, T. L.; Heterocyclic Chemistry; $2^{\text {nd }}$ ed., Longman; London 1994; p 345.

145. March, J.; Advanced Organic Chemistry, $3^{\text {rd }}$ ed., New York 1985, p 921.

146. Iranpoor, N.; Kazemi, F.; Synthesis 1996, 821.

147. Iranpoor, N.; Zeynizadeh, B.; Synth. Commun. 1998, 28, 3913.

148. Mohammadpoor-Baltork, I.; Aliyan, H.; Synth. Commun. 1998, 28, 3943.

149. Borden, W. T.; J. Am. Chem. Soc. 1987, 109, 5524.

150. Robins, M. J.; Lewandowska, E.; Wnuk, S. F.; J. Org. Chem. 1998, 63, 7375.

151. Clive, D. L. J.; Wickens, P. L.; Sgarbi, P. W. M. J. Org. Chem. 1996, 61, 7426.

152. Clive, D. L. J.; Sgarbi, P. W. M.; Wickens, P. L.; J. Org. Chem. 1997, 62, 3751.

153. Antonov, K. V.; Konstantinova, I. D.; Miroshnikov, A. I.; Nucleosides \& Nucleotides 1998, 17, 153.

154. Tewson, T.; J. Org. Chem. 1983, 48, 3507.

155. Berridge, M. S.; Franceschini, M. P.; Rosenfeld, E.; Tewson, T.; J. Org. Chem. 1990, 55, 1211.

156. Denmark, S. E.; J. Org. Chem. 1981, 46, 3144.

157. Lowe, G.; Salamone, S. J.; J Chem. Soc. Chem. Commun. 1983, 23, 1392.

158. Robins, M. J.; Hansske, F.; Wnuk, S. F.; Kanai, T.; Can. J. Chem. 1991, 69, 1468.

159. Saito, I.; Ikehira, H.; Kasatani, R.; Watanabe, M.; Matsuura, T.; J. Am. Chem. Soc. 1986, 108, 3115.

160. Deshayes, H.; Pete, J.-P.; Portella, C.; Scholler, D.; J. Chem. Soc. Chem.Commun. 1975, 439.

161. Deshayes, H.; Pete, J.-P.; Portella, C.; Tetrahedron Lett. 1976, 2019.

162. Portella, C.; Deshayes, H.; Pete, J.-P.; Scholler, D.; Tetrahedron 1984, 40, 3635.

163. Prudhomme, D. R.; Wang, Z.; Rizzo, C. J.; J. Org. Chem. 1997, 62, 8257.

164. Joshi, B. V.; Rao, T. S.; Reese, C. B.; J. Chem. Soc., Perkin Trans. 1 1992, 2537.

165. Telles Grillo, M. L.; Magalhães, P. J.; Quim. Nova 1994, 17, 342 .

166. Schechter, M.; Ciência Hoje 1994, 18, 54.

167. Cowley, G.; Newsweek 1993, 22 de março, 43. 